\title{
Seasonal Variation and Age-related Changes in the Relative Permittivity of Concrete Bridge Decks on Korea Expressways
}

\author{
Ji-Young Rhee ${ }^{1)}$, Seong-Hoon $\mathrm{Kee}^{2)}$, Hong-Sam Kim ${ }^{1)}$, and Jae-Jin Choi $^{3), *}$ (1)
}

(Received February 15, 2017, Accepted January 7, 2018)

\begin{abstract}
The purposes of this study were to investigate the seasonal variations in the relative permittivity of actual concrete bridge decks of various ages on Korea expressways, and to propose a practical way to calibrate two critical effects, to assess the condition of the concrete bridge decks with better accuracy. For these purposes, fifty-three actual concrete bridge decks on Korea expressways were scanned using an air-coupled ground penetrating radar (GPR) system, and the relative permittivity of the concrete was evaluated from the GPR data in the field. A statistical analysis showed that the relative permittivity of the concrete bridge decks in Korea are closely correlated with seasonal changes and concrete ages. For concrete bridge decks aged 10 years or older, the effect of concrete age was not as significant as that of relative humidity of the air on relative permittivity of concrete. Based on the results, a simple calibration process was proposed to suppress the effects of seasonal variation and age of concrete on the measured relative permittivity of the concrete decks on actual bridges. As will be discussed, the resulting relative permittivity method produced better agreement with the current condition of the concrete bridge decks as determined by visual inspection and other complementary methods (energy attenuation of GPR signals and corrosion potential measurements) than without the calibration process.
\end{abstract}

Keywords: ground-penetrating radar, relative permittivity, concrete, seasonal variation, concrete age, deterioration.

\section{Introduction}

Bridges are treated as critical nodes in the highway system, and as a result more importance is generally placed on them in the strategic planning of infrastructure maintenance than on most other components in the transportation network (Gucunski et al. 2013). Furthermore, because bridge decks are directly exposed to the external environment, they experience a more rapid loss in integrity over time compared with other bridge components. They are subject to deterioration mechanisms from various factors, including poor initial quality, chloride-induced damages, freeze-thawing cycle-induced stresses, fatigue, and overloading. Infrastructure management agencies in many countries currently dedicate a considerable portion of their budget associated with bridges to the restoration, rehabilitation, and maintenance of bridge decks. To ensure the efficient and effective allocation of limited budgets and resources, the priorities of

\footnotetext{
${ }^{1)}$ Korea Expressway Corporation, Hwaseong, South Korea.

${ }^{2)}$ Department of Architectural Engineering, Dong-A University, Busan, South Korea.

${ }^{3)}$ Department of Civil \& Environmental Engineering, Kongju National University, Kongju, South Korea. *Corresponding Author; E-mail: jjchoi@kongju.ac.kr Copyright (c) The Author(s) 2018. This article is an open access publication
}

management actions are generally based on the current condition of the bridge decks (Barnes et al. 2008; Lee et al. 2015). For these reasons, it is of great importance in many countries to develop and implement effective inspection methods for reliable, consistent and rapid condition assessment and/or performance monitoring of bridge decks in the field.

Ground penetrating radar (GPR) is a nondestructive testing (NDT) tool that is commonly used as a rapid and non-invasive inspection tool for bridge decks both in the laboratory and the field. A transient electromagnetic pulse transmitted from a transmitter antenna in a GPR system is penetrated into the concrete, and the reflected pulse from an interface with a dielectric mismatch is detected by a receiver antenna. In GPR applications, the relative permittivity $\varepsilon_{r}$ is one of the critical parameters used to determine the propagation velocity of an electromagnetic wave $V_{m}$ in a material. Knowing that the propagation velocity in air $C_{a i r}$ is, about $300 \mathrm{~mm} / \mathrm{ns}, V_{m}$ in a material can be approximated using the following equation:

$$
V_{\mathrm{m}}=\frac{C_{\text {air }}}{\sqrt{\varepsilon_{\mathrm{r}}}}
$$

Subsequently, the depth of a reflector $d$ is calculated from the following equation (Balanis 1989)

$$
d=\frac{C_{a i r} T}{2 \sqrt{\varepsilon_{r}}}
$$


where, $T$ is the two-way travel time of an electromagnetic wave in a material. It is necessary to obtain the reliable relative permittivity values of materials in order to accurately assess the condition of the targets embedded in the media.

Many researchers have successfully visualized the potential of chloride-induced deterioration (or other corrosive environments) in new and old concrete by measuring the energy attenuation of the reflected electromagnetic waves at the top of the reinforcing-bar (rebar) (Barnes et al. 2008; Tarussov et al. 2013; Hasan and Yazdani 2014; Varnavina et al. 2015; Dinh et al. 2016). The corrosive environments with higher moisture and chloride contents could be identified and differentiated because they were more highly attenuated than sound sections (Dinh et al. 2016). To obtain reliable and consistent interpretation, the effect of depth should be appropriately removed from the attenuation measurements. The calibration process generally requires information about the relative permittivity of the concrete. It is recommended that the relative permittivity of the concrete be set by using several samples or bridge deck plans for calibration purposes; however, this is labor-intensive and does not accurately reflect the as-built conditions. Therefore, the relative permittivity of normal concrete is generally assumed to be proper values between 5 and 10 (ASTM D 6432 2011), however, this may not be always applicable to concrete under different conditions.

In Korea, GPR has been used for assessing the condition and monitoring the performance of bridge decks in the Korean expressway system (Suh et al. 1998), after it was first introduced by the Korea Expressway Corporation in 1997. The relative permittivity of concrete measured based on the surface reflection method (Maser and Scullion 1991), and is directly used as a measure of the severity of deterioration in the top surface of the concrete bridge deck.

Old concrete bridge decks can have various types of damage, including cracks, fractures and enhanced porosity (Suh et al. 2004a). Higher chloride content, which results in increased water content in the concrete, consequently increases the value of the relative permittivity of the concrete. As a rule of thumb, tested regions exhibit a relative concrete permittivity equal to or greater than 12.0 are interpreted as potentially deteriorated (Suh et al. 2000).

However, the relative permittivity of concrete is not just dependent on the severity of deterioration, but also on other influential factors, such as the age of the concrete, moisture content, the frequency of the electromagnetic pulse, and etc. (ASTM D 6432 2011). In particular, the relative permittivity of bare concrete decks measured using the surface reflection method at the concrete surface, can be strongly affected by the relative humidity of the air, which may pose difficulties in accurately interpreting the concrete conditions.

There have been a number of previous studies which have investigated the effects of influential factors on the relative permittivity of concrete (Daniels 2004), and some of these researchers have provided mathematical models that can be used to predict the effects (Bourdi et al. 2012; Yanhui et al. 2012). However, most of the studies have been performed in the laboratory, and could not appropriately take into account the actual field effects, such as seasonal variations and agerelated changes over the long-term.

The primary objectives of this study were to investigate seasonal variations and age-related changes in the relative permittivity of actual concrete bridge decks of various ages on Korea expressways, and to propose a practical way to calibrate the effects of the two critical parameters used for assessing the condition of the concrete bridge decks, for better accuracy. The data in this study were obtained from fifty-three concrete bridge decks in public service, using an air-coupled GPR system with $1 \mathrm{GHz}$ antennas. Only bare concrete decks were included in this study because the presence of an asphalt concrete overlay results in a completely different deterioration mechanism, and accordingly, different influential factors would need to be involved in the GPR survey (e.g., the interface conditions between the overlay and the top concrete) (Rhee and Choi 2017; Rhee et al. 2017).

A statistical study showed that the relative permittivity of actual concrete bridge decks in Korea is affected by seasonal variation and concrete ages. As will be discussed, the resulting values provided by the proposed method are in better agreement with the concrete conditions determined by visual inspection and other complementary methods (energy attenuation of GPR signals and corrosion potential measurements) than the case without the calibration process.

\section{Data Collection on Concrete Bridge Decks in the Field}

\subsection{Description of Bridges}

A total of sixty GPR tests were performed on concrete decks on fifty-three different bridges in public service from 2003 to 2013. In Korea, bridges were designed and constructed in the 1980's had bare concrete decks without asphalt concrete overlay. Test bridges include the ' 88 line (1983, 1984)', 'the Branch of Jungbu Naeryuk line (1984)', 'Honamwidening line (1986, 1987)', 'Jungbu line (1987)', 'Gyeongbu line (1987, 1992)', and 'Jungbu Naeryuk line (2003, 2004)'. Most of the bare concrete bridge decks in the 1980's were constructed with a designed compressive strength of $27 \mathrm{MPa}$, and a designed air content of $5 \%$. At that time, natural aggregates from rivers and/or quarries were used for the concrete mixture. In contrast, in the 1990's almost bridges were constructed with an asphalt concrete overlay. Then, reapplication of bare deck bridges started on the Jungbu Naeryuk line in the 2000's with the same compressive strength of concrete as was used in the 1980's, but with air content of $4.5 \%$. Coarse aggregates used in the concrete were taken from rivers and the construction sites of the bridges (The Ministry of Construction Division 1984, Construction Div. 1988, Construction Planning Department 2004a, b,).

Information from the test bridges and specific test conditions are summarized in Table 1. The marks ' $\mathrm{N}$ ' and ' $\mathrm{S}$ ' following after the bridge name stand for north and southbounds lanes in the Korea expressway system. The mark ' $R$ ' 


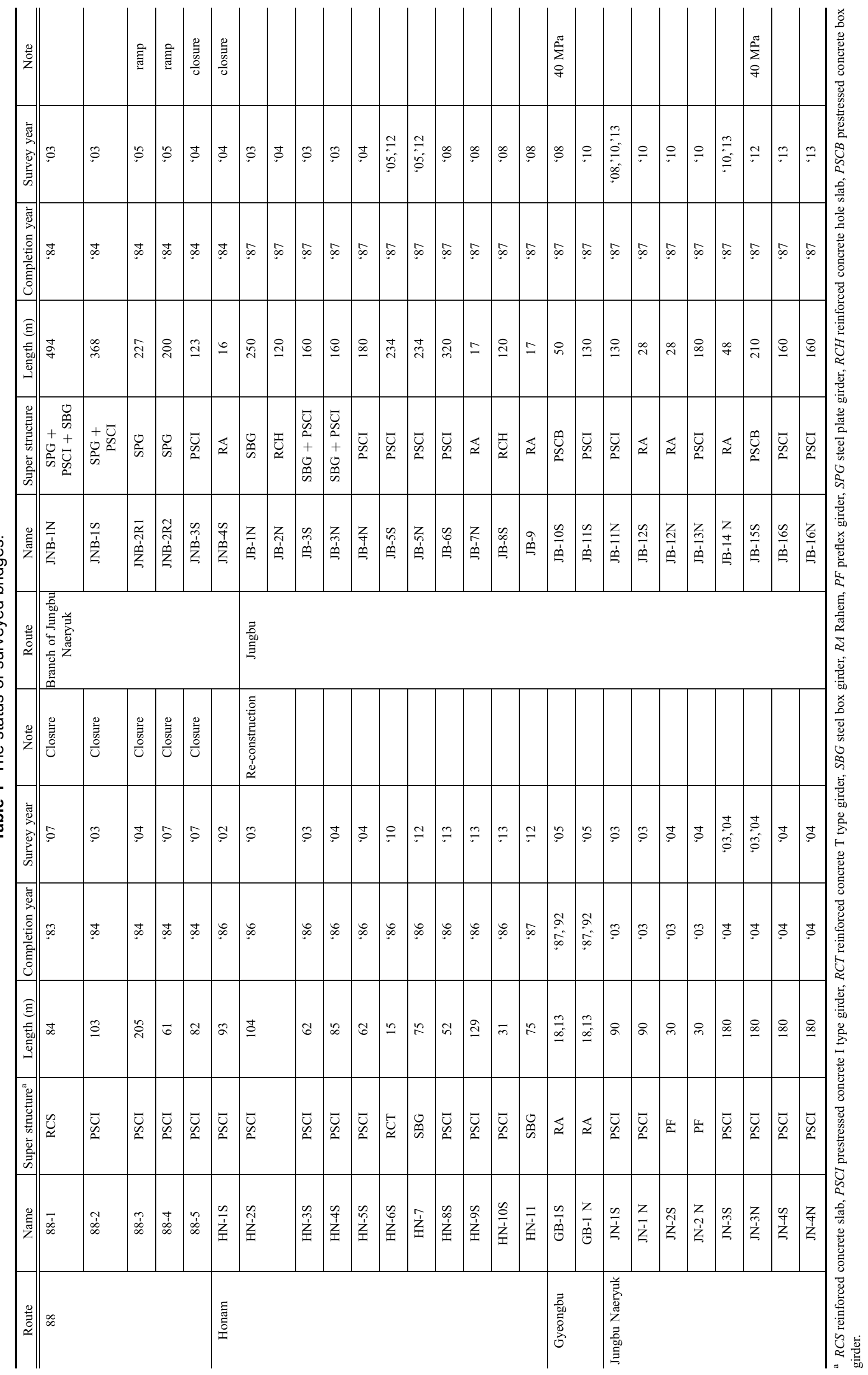


stands for the ramp bridge. The service life of the lanes on bridge GB-1 N and GB-1S differ due to the fact that some lanes were originally constructed in 1987 and some other lanes were added later, in 1992. Bridges JB-5S, JB-5 N, JB$11 \mathrm{~N}, \mathrm{JB}-14, \mathrm{JN}-3 \mathrm{~S}$, and JN-3N were tested more than twice using the same equipment with $1 \mathrm{GHz}$ air-coupled antennas. Bridges JB-10S and JB-15S, constructed with a type of prestressed concrete box girder, were designed with a compressive strength of $40 \mathrm{MPa}$ and air content of $2 \%$. The other bridges were designed with a compressive strength of $27 \mathrm{MPa}$. The designed air content of the bridges on the Jungbu Naeryuk line was $4.5 \%$, but was $5 \%$ on the others.

\subsection{Survey Method}

An air-coupled GPR system manufactured by Geophysical Survey Systems, Inc. (GSSI) was used for the highway bridge surveys in Korea (see Fig. 1). The GPR hardware used in the air-coupled GPR system is composed of aircoupled antennas with transmitter/receiver electronics (horn antenna type), cables, a GPR control unit, pulse encoder and accessory equipment. All of the bridges were scanned using a $1 \mathrm{GHz}$ air-coupled, four-array antenna suspended on a van at a distance of 0.45 meters above the surface of the bridge decks. The non-contact features of the air-coupled GPR system enabled consistent measurements and full speed data collection $(80-100 \mathrm{~km} / \mathrm{h})$ regardless of the surface condition of the bridges or interference from traffic. The sampling rate was $10-12$ scans $/ \mathrm{m}$, which resulted in a total of between 3607 and 45,753 samples per bridge.

In operation, a circuit within the radar control unit generates a sequence of trigger pulses, which are sent to the transmitter. The transmitter produces output pulses radiating into the concrete deck, and the receiving antenna detects the electromagnetic waves reflected from the interfaces where the electromagnetic properties of the materials change (Fig. 2). These signals are sent to the control unit for analysis of the materials' properties and locations. RADAN ${ }^{\circledR}$ (GSSI 2009), the commercial software provided by GSSI, was chosen to analyze the measured data and generate GPR B-scan images (Fig. 3).

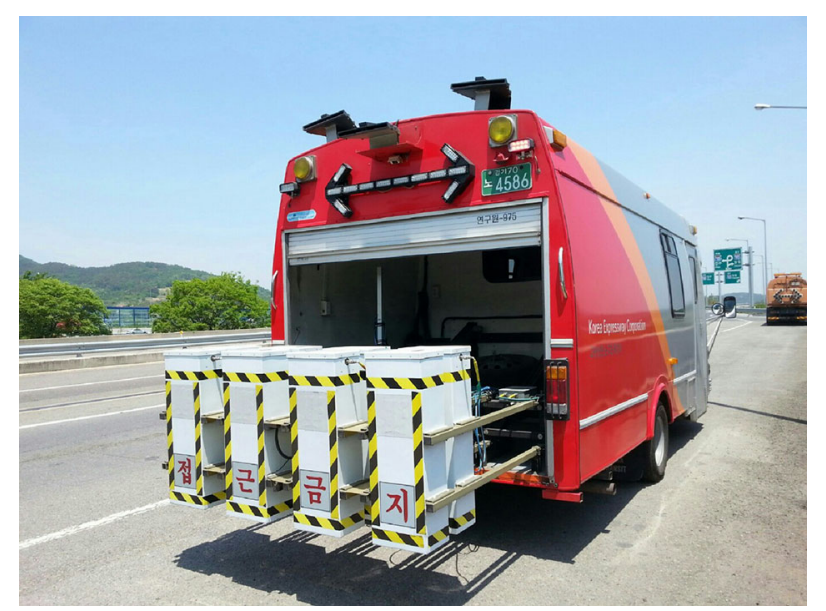

Fig. 1 Air-coupled GPR system used for concrete bridge deck survey.

\subsection{Relative Permittivity Estimation Using GPR Data in the Field}

In this study, the relative permittivity of concrete was estimated using the surface reflection method (Maser and Scullion 1991). The theoretical reflection coefficient $\left(R_{t}\right)$ of an electromagnetic wave at the surface of a material is expressed as follows,

$$
R_{t}=\frac{1-\sqrt{\varepsilon_{r}}}{1+\sqrt{\varepsilon_{r}}}
$$

In practice, the reflection coefficient is also determined by comparing the relative amplitude of the reflected wave from the surface of the concrete $A_{c}$ to that from the surface of a perfect electric conductor (i.e., in this study, a large metal sheet, representing $100 \%$ reflection) $A_{P}$ as follows,

$$
R_{m}=\frac{A_{c}}{A_{p}}
$$

where $R_{m}$ is the measured reflection coefficient. From Eqs. (3) and (4), the relative permittivity of concrete can be summarized as follows,

$$
\sqrt{\varepsilon_{c}}=\frac{A_{p}+A_{c}}{A_{p}-A_{c}}
$$

The relative permittivity of materials is a complex, frequency-dependent quantity with real (storage) and imaginary (loss) components. However, the bare concrete decks in this study were exposed to air, and all of the GPR surveys were conducted on a dry surface during the daytime; there was no precipitation within $24 \mathrm{~h}$ before the GPR survey, in accordance with the GPR field survey protocol of the Korea Expressway Corporation. As a result, the surveyed concrete was reasonably assumed to be a dry and low conductive (or low loss) material (Daniels 2004). Therefore, the relative permittivity of the concrete was simplified to a constant and the loss term was ignored in this study.

\section{Results and Discussion}

The average relative permittivity of each bare deck concrete bridge was calculated excluding the outliers generated by steel joints. Additionally, the averages were calculated separately for similar bridges of different ages.

\subsection{Age-Related Changes}

Figure 4 shows the variation in the relative permittivity of bare deck concrete measured with the $1 \mathrm{GHz}$ antenna array as the age of the concrete increases. The relative permittivity of the concrete in the eight new bridges, presented as open rectangles in Fig. 4, ranges between 11 and 16 with an average of 13.3 and a standard deviation of 1.5 , and the values rapidly decrease within a half year. The new bridges were tested before or just after opening-to-traffic using a fixed antenna frequency (i.e., $1 \mathrm{GHz}$ ), and no precipitation on the bridges was recorded within $24 \mathrm{~h}$ before the GPR 

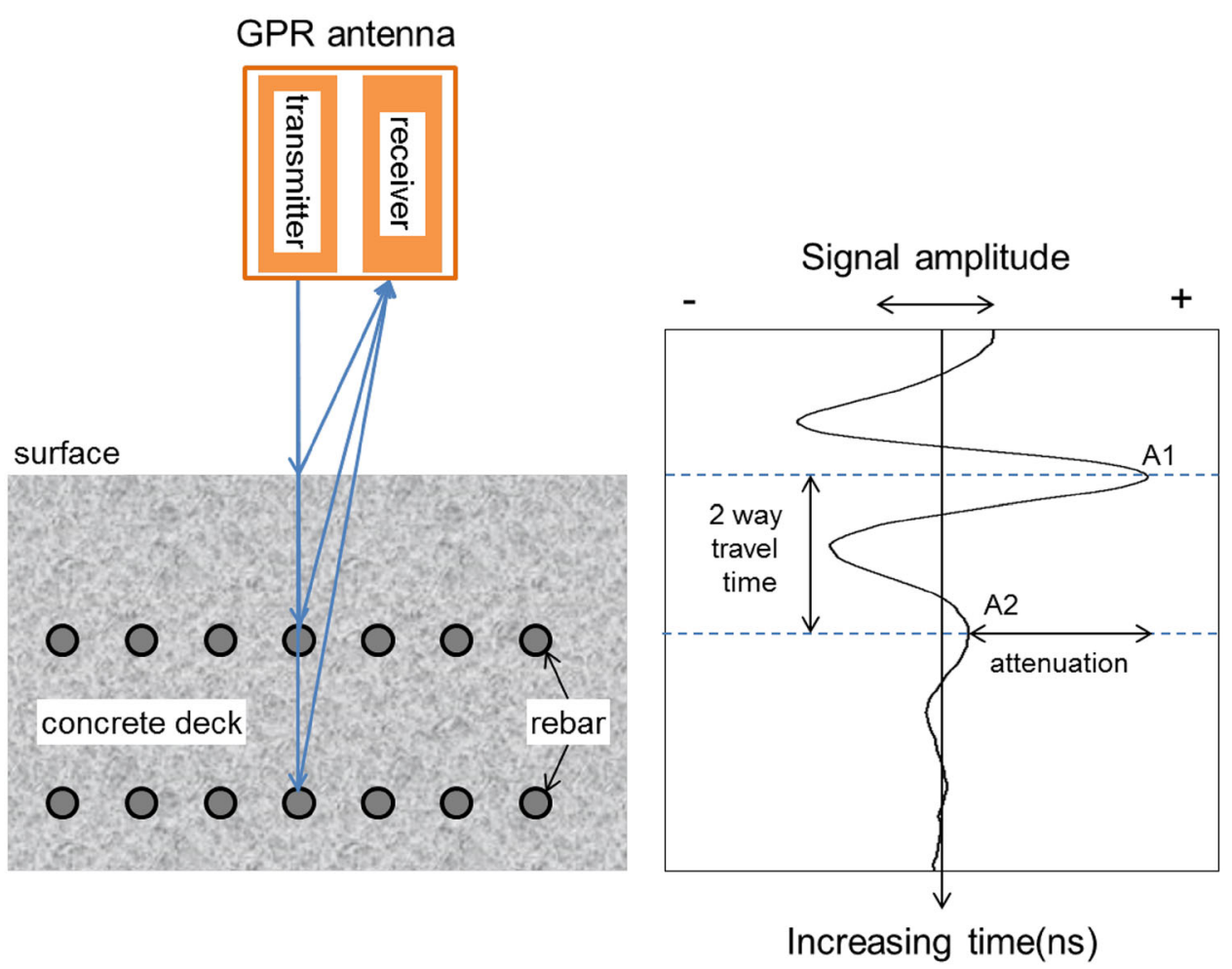

Fig. 2 GPR scanning on a bare concrete deck: a possible path of EM waves in concrete bridge decks and b typical signal measured from a receiver antenna.

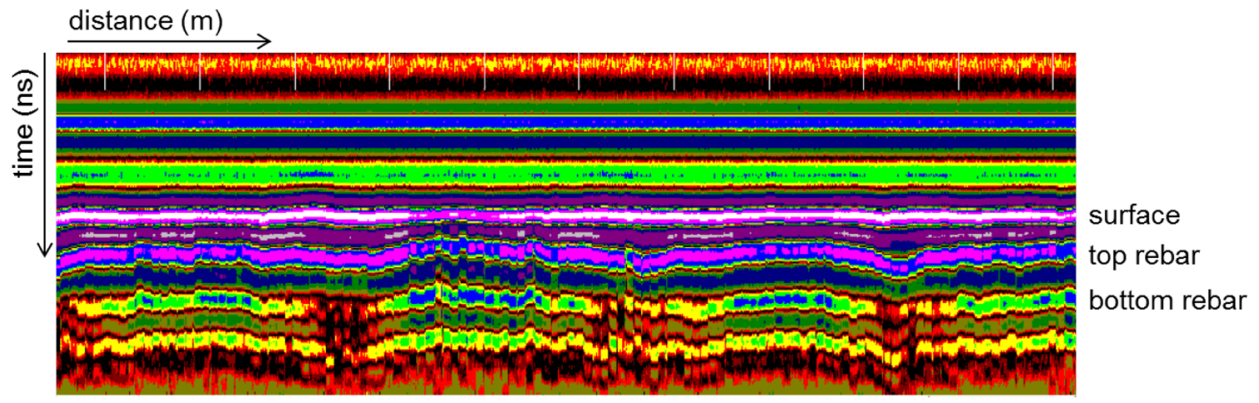

Fig. 3 Typical GPR B-scan image of a section of a RC deck measured by an air-coupled GPR.

scanning. The relative permittivity of concrete depends on its component materials (Klysz et al. 2008; Bourdi et al. 2012) such as types of cement, aggregates, admixtures, air and water. Among these, the most influential factor is water, which has a much higher relative permittivity (i.e., 81) than the other components in concrete. Young concrete has plenty of water in the concrete pore system, which generally leads to higher relative permittivity than that found in mature concrete in old bridges.

On contrary, the relative permittivity of the concrete in older bridges, aged 10 years or more, is presented as open circles in Fig. 4, and ranges between 4 and 12, with an average of 8.4 and a standard deviation of 1.6. This is about $60 \%$ of the values found in concrete aged less than 1 year. These results can be explained by the microstructure of the concrete, which becomes stable as the residual water is evaporated with aging. Consequently, the relative permittivity of concrete gradually decreases, and converges to a certain range as the age of the concrete increases.
It was attempted to obtain a simple mathematical model to express the relationship between the relative permittivity and age of concrete in all bridge decks on Korea expressways considered in this study by using a non-linear regression analysis, as follows,

$$
\varepsilon_{r, c}^{A g e}=-1.38 \ln \left(\text { Age }_{\text {conc }}\right)+12.89\left(R^{2}=0.62\right)
$$

where $A g e_{\text {conc }}$ is the age of the concrete at the time of the GPR measurements. However, there was relatively wide scattering of the relative permittivity data of older (aged 10 years or more) deck concretes. The wider scattering of the relative permittivity of the old deck concretes implies that there are other influential factors on the relative permittivity of concrete along with the age-related effect. The effect of seasonal variation is discussed in the next section.

\subsection{Seasonal Variation}

Figure 5 shows the annual changes in the relative permittivity of bare deck concrete with the level of relative 

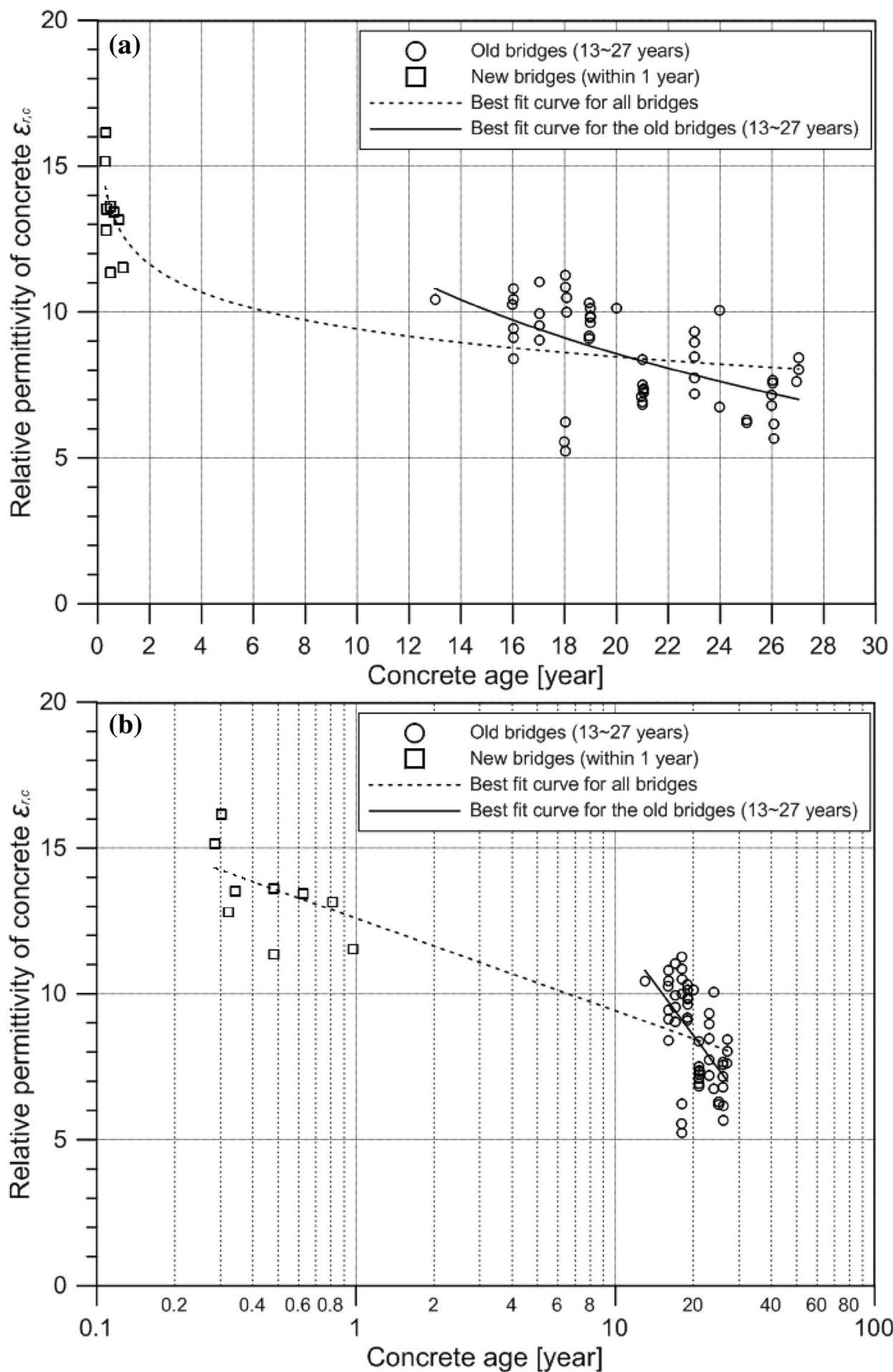

Fig. 4 Variation of relative permittivity of concrete with concrete age before considering the effect of relative humidity of air: a linear and $\mathbf{b}$ logarithmic scale in the horizontal axis for concrete age.

humidity in the air in the Korean climate. The relative permittivity of concrete in the old bridges appears to have seasonal variations. The average relative permittivity of concrete gradually decreases from 8.2 to 5.7 as the month of measurement changes from February to April. Subsequently, the value gradually increases to 9.2 between July and August, and decreases again as the month of measurement goes further. Therefore, it is reasonable to say that the seasonal variation in the relative permittivity of concrete is mainly related to changes in the water content in the concrete. The water content of concrete exposed to the weather depends on multiple variables, including air temperature, relative humidity, concrete temperature, wind velocity and the amount of water from outside (Berhane 1984). In particular, the upper part of the concrete, which is the region of interest in the air-coupled GPR survey, is strongly affected by external weather conditions.

It is of interest to determine how the critical weather parameters affect the relative permittivity of the concrete in actual bridge decks. Figure 6 is a plot representing the 


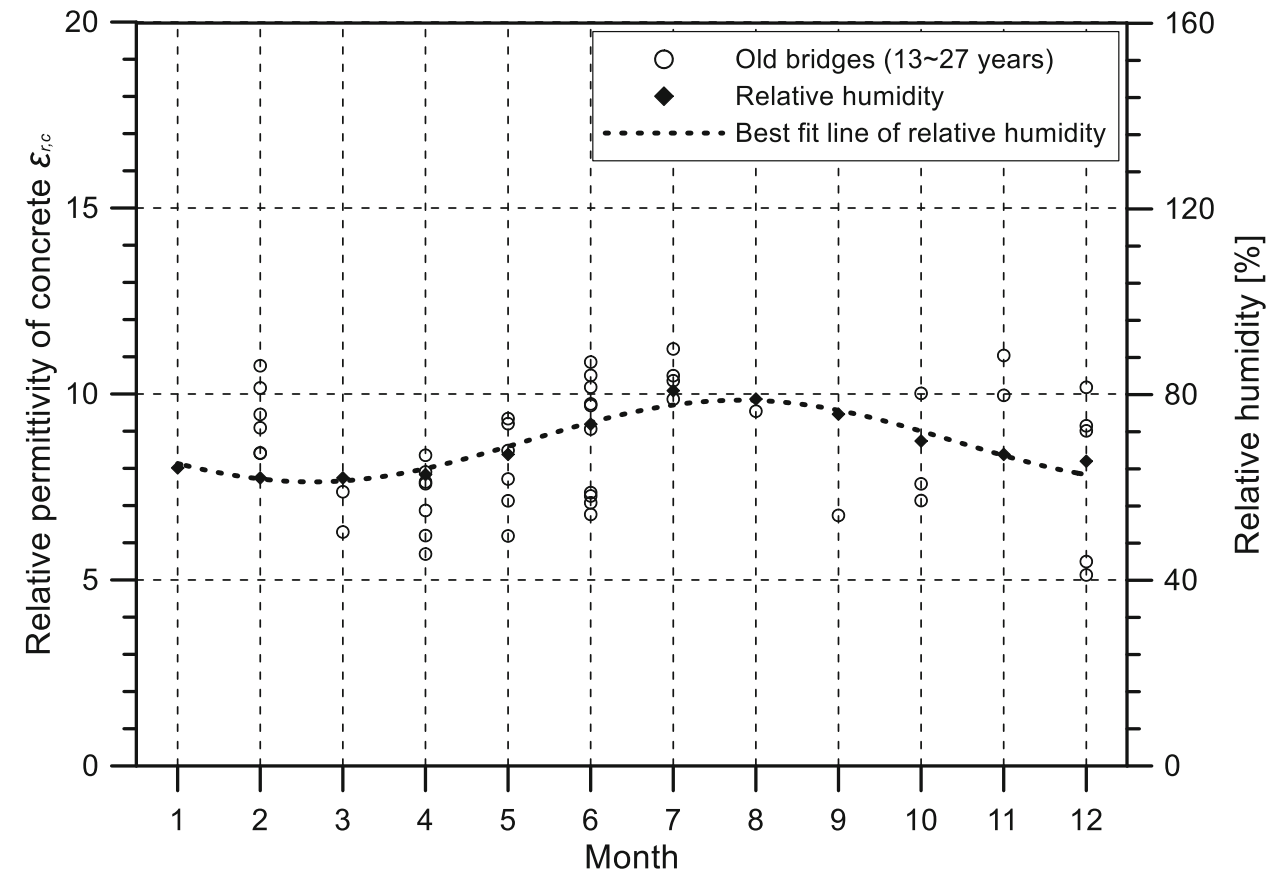

Fig. 5 Variation of relative permittivity of concrete by month, and the variation in the relative humidity of the air by month.

(a)

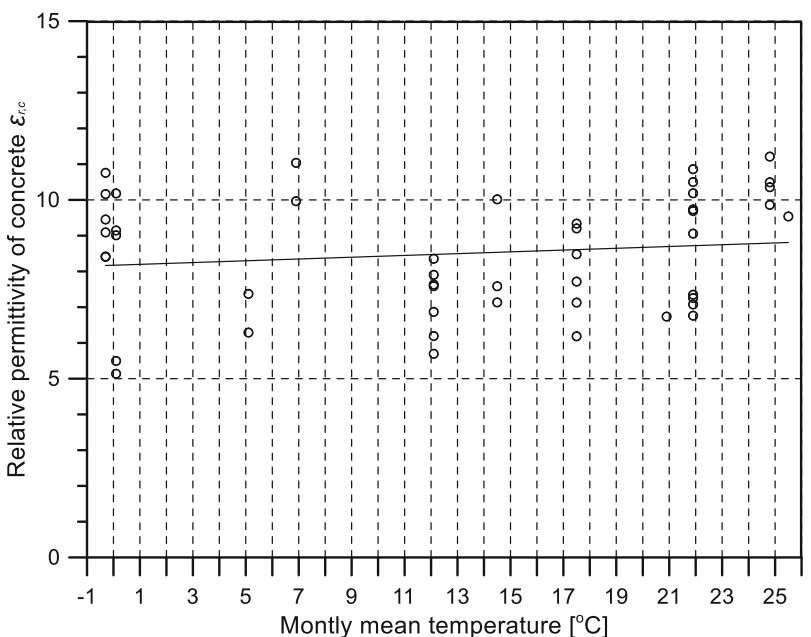

(c)

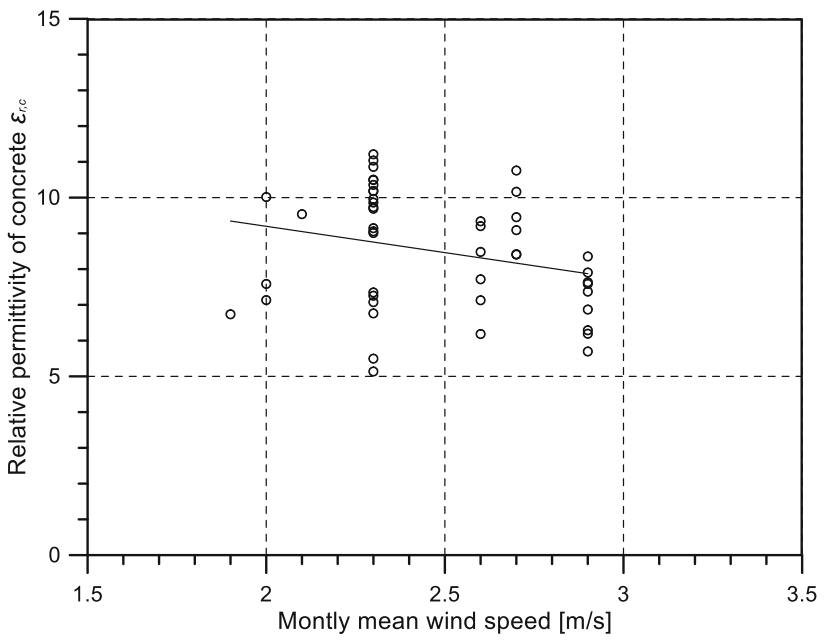

(b)

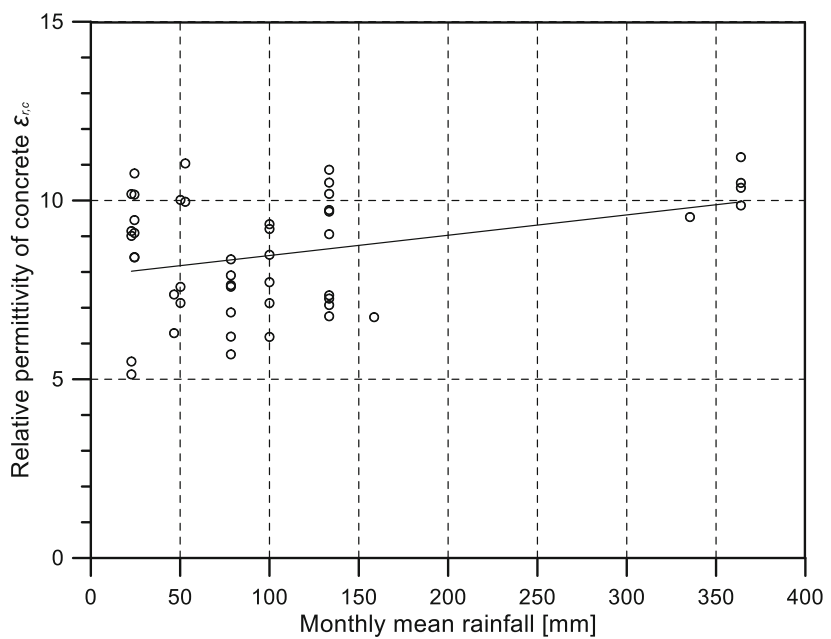

(d)

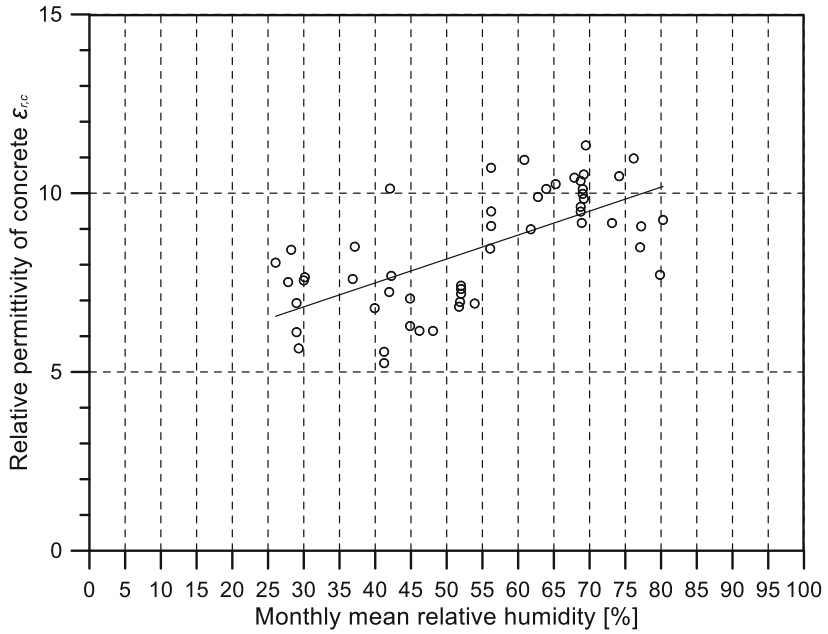

Fig. 6 Variation of the relative permittivity of concrete with different weather factors; a monthly mean temperature, $\mathbf{b}$ monthly mean rainfall, $\mathbf{c}$ monthly mean wind speed, and $\mathbf{d}$ monthly mean relative humidity. 
relative permittivity of concrete with respect to monthly mean weather data over 30 years (from 1981 to 2010) as reported by the Korea Meteorological Administration (Accessed 2017). The best fitting lines to express the relationship between the relative permittivity of the concrete and each type of weather data (temperature, wind speed, rainfall or relative humidity) were obtained by linear regression analyses, and are presented in the same figure. Table 2 summarizes the numerical equations used for the best fit lines and R-squares.

Among the four relations, the most influential factor affecting the changes in the relative permittivity of the concrete was found to be the relative humidity of the air. Concrete bridge decks in Korea expressways have thicknesses ranging between 200 and $400 \mathrm{~mm}$, and the concrete cover depth is about $100 \mathrm{~mm}$. There is a compatibility condition for water at the interface between the concrete and air. As a result, the water ratio in the cover concrete is close to the relative humidity of the air. The moisture level of pores in the cover concrete vary with the relative humidity; and accordingly, the relative permittivity will increase or decrease depending on the relative humidity. Statistical analyses show that the variation in relative permittivity is affected by relative humidity or rainfall, while, it is less affected by temperature or wind speed.

Figure 7 shows the relationship between relative permittivity of concrete on the older bridges and the relative humidity measured at the weather stations near the bridge locations by Korea Meteorological Administration. It has been reported that the relative permittivity of geo-materials (e.g., clay and silty soils) shows a non-linear reduction when moisture content falls to the level of dry conditions. This is because water molecule mobility is restricted by interaction with the surface charges of the concrete aggregates (Saarenketo 1998). In this study, an exponential curve was used to describe the non-linear behavior of the relative permittivity in relation to the water content in the concrete. In the figure, data from different expressways are represented with different symbols, and the best fitted lines for each expressway route were obtained from non-linear regression analyses. Table 3 summarizes the numerical equations for best fit curves and R-squares. Interestingly, the three best-fit curves were close to each other, which connoted that the effect of different expressways did not much affect the effect of relative humidity of air on the relative permittivity of concrete in bridge decks.

\subsection{Effect of Relative Humidity on Relative Permittivity of Concrete}

The effect of relative humidity of air (RH) on relative permittivity of concrete in the old bridges is investigated in this section. As described before in Sect. 3.1, the relative permittivity of concrete in new bridges was primarily influenced by age-related effect (i.e., evaporable water in concrete during cement hydration process). Therefore, the effect of relative humidity of air on the early age concrete is disregarded. Old bridges were subdivided into two groups by the age at the moment of GPR measurements to investigate the contribution of concrete age on the effect of the relative humidity: Figs. $8 \mathrm{a}$ and $\mathrm{b}$ show the GPR data results for bridges with concrete ages of 13 - 20 years (group 1) and 21-30 years (group 2), respectively. In Fig. 8a, multiple best fit lines for the concrete ages of 16, 17 and 18 years old, which include at least three data points of the GPR measurements, show a similar trend for the similar concrete ages. These GPR data of this study indicated that the effect of concrete age was not as significant as the contribution of relative humidity on relative permittivity of concrete. For group 1, an approximate equation to express the relationship between relative permittivity of concrete and relative humidity of air was obtained by a linear regression analysis as follows,

$$
\varepsilon_{r, c}^{R H}=0.14 R H+0.53\left(R^{2}=0.72\right)
$$

where $\mathrm{RH}$ is the relative humidity of air.

On the other hand, Fig. $8 \mathrm{~b}$ shows the variation of relative permittivity of concrete older than 21 years is less sensitive to the change of relative humidity of air, and the effect of concrete age is not clear. From Fig. $8 \mathrm{a}$ and b, a practical equation to express the relationship between relative permittivity of concrete and relative humidity of air is expressed as follows,

$$
\varepsilon_{r, c}^{R H}=\left(\begin{array}{cc}
0.14 \mathrm{RH}+0.53 & \text { for } R . H . \geq 50 \% \\
7.58 & \text { for R.H. }<50 \%
\end{array}\right)
$$

\subsection{Effect of Concrete Age on Relative Permittivity of Concrete}

The effect of concrete age on the variation of relative permittivity of concrete in old bridges was investigated in this section. As aforementioned, it is reasonable to assume that relative permittivity of concrete in new bridges are more

Table 2 Summary of equations for best fit lines and goodness of fit (R-squares).

\begin{tabular}{c|c|c}
\hline \multirow{2}{*}{ Weather factor } & \multicolumn{2}{|c}{ Old bridges } \\
\cline { 2 - 3 } & Best fit lines & $\mathrm{R}^{2}$ \\
\hline \hline Monthly mean temperature & $\mathrm{Y}=0.0025 \mathrm{X}+8.17$ & 0.02 \\
\hline Monthly mean rainfall & $\mathrm{Y}=0.0056 \mathrm{X}+7.89$ & 0.11 \\
\hline Monthly mean wind speed & $\mathrm{Y}=-1.47 \mathrm{X}+12.14$ & 0.07 \\
\hline Monthly mean relative humidity & $\mathrm{Y}=0.066 \mathrm{X}+4.81$ & 0.43 \\
\hline
\end{tabular}

$X$ each weather factor and $Y$ relative permittivity of concrete. 


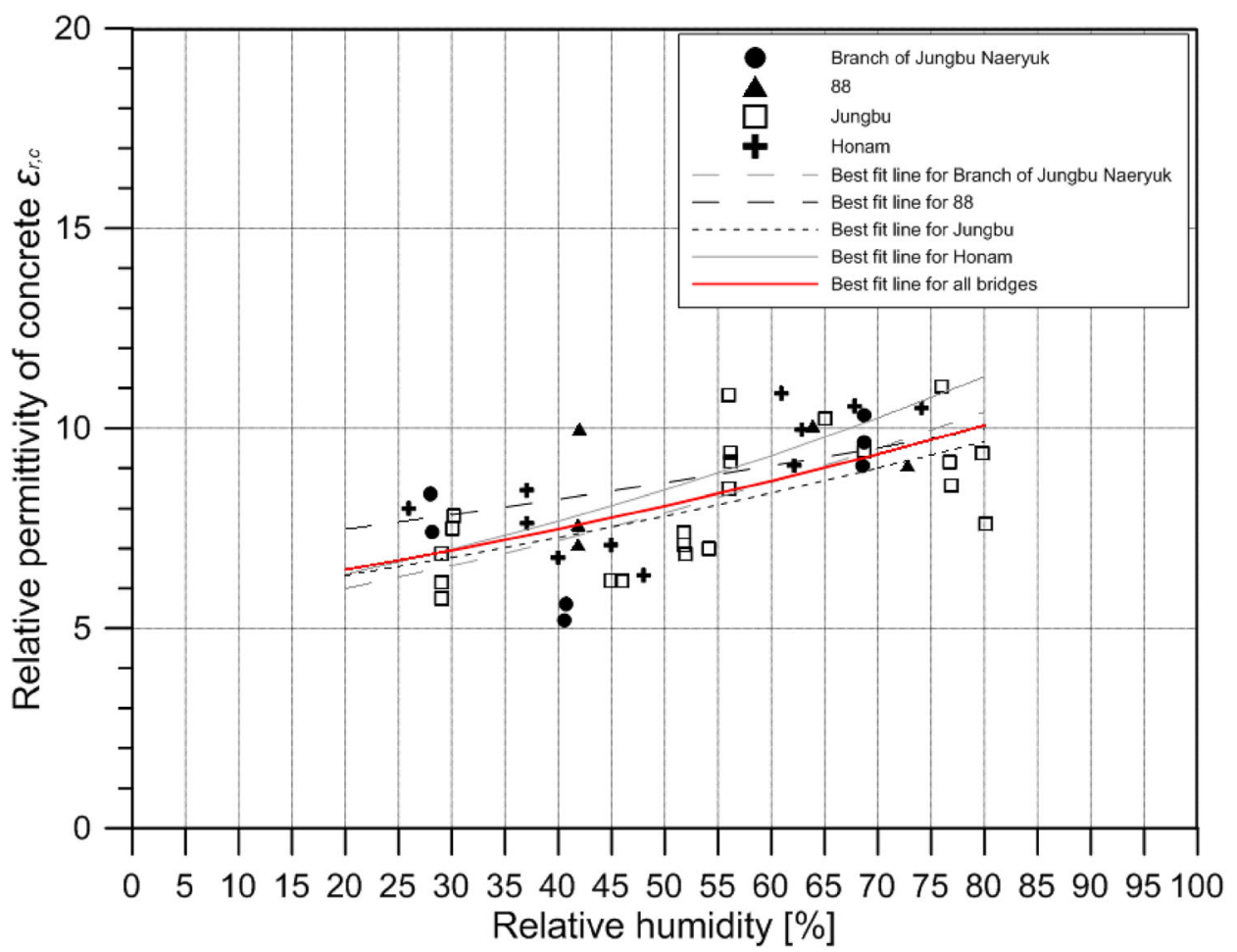

Fig. 7 Variation of relative permittivity of concrete with relative humidity for 4 different old expressway routes.

Table 3 Summary of equations for best fit lines and goodness of fit (R-squares) for old bridges.

\begin{tabular}{c|c|c}
\hline Bridges & Best fit lines & $\mathrm{R}^{2}$ \\
\hline \hline Branch of Jungbu Naeryuk & $\mathrm{Y}=4.98 e^{0.0092 x}$ & 0.46 \\
\hline 88 & $\mathrm{Y}=6.79 e^{0.0048 x}$ & 0.23 \\
\hline Jungbu & $\mathrm{Y}=5.48 e^{0.0071 x}$ & 0.41 \\
\hline Honam & $\mathrm{Y}=5.23 e^{0.0096 x}$ & 0.40 \\
\hline All bridges & $\mathrm{Y}=5.57 e^{0.0074 x}$ & \\
\hline
\end{tabular}

$X$ relative humidity of the air and $Y$ relative permittivity of concrete.

influenced by evaporable water in concrete during cement hydration process than the seasonal variations, the effect of relative humidity of air on the early age concrete was disregarded. Also, old bridges were subdivided into three groups of similar relative humidity of air to investigate the contribution of relative humidity on the effect of concrete age; group 1 for the relative humidity lower than $50 \%$, group 2 for the relative humidity between $50 \%$ and $60 \%$, and group 3 for the relative humidity greater than $60 \%$. Presented in Fig. 9 is the variation of relative permittivity of concrete in the three different groups of old bridges by the concrete age at the time of GPR measurements: data from groups 1,2 and 3 are presented with unfilled (open) rectangles, diamonds, and triangles, respectively. Overall, for the same concrete age group, relative permittivity of concrete had a higher value as relative humidity of air increased.

A calibration factor was proposed in this study to suppress the contribution of relative humidity as expressed in the following,

$$
\gamma(R H)=\varepsilon_{r, c}^{R H}(50) / \varepsilon_{r, c}^{R H}(R H)
$$

where $\gamma(\mathrm{RH})$ is the calibration factor to suppress the effect of relative humidity on relative permittivity of concrete, and $\varepsilon_{r, c}^{R H}(50)$ is the reference relative permittivity of concrete corresponding to the relative humidity of $50 \%$. The contribution of relative humidity can be replaced by multiplying relative permittivity values by the calibration factor obtained using Eq. (9).

Figure 10 shows the variation of relative permittivity of concrete with concrete age after suppressing the relative humidity effect. The variation of relative permittivity of concrete tended to slowly decrease as the concrete age increased, which indicated that the effect of concrete age on the relative permittivity of concrete was not significant when the concrete age was greater than 10 years.

A simple mathematical model to express the relationship between the relative permittivity and age of concrete on 


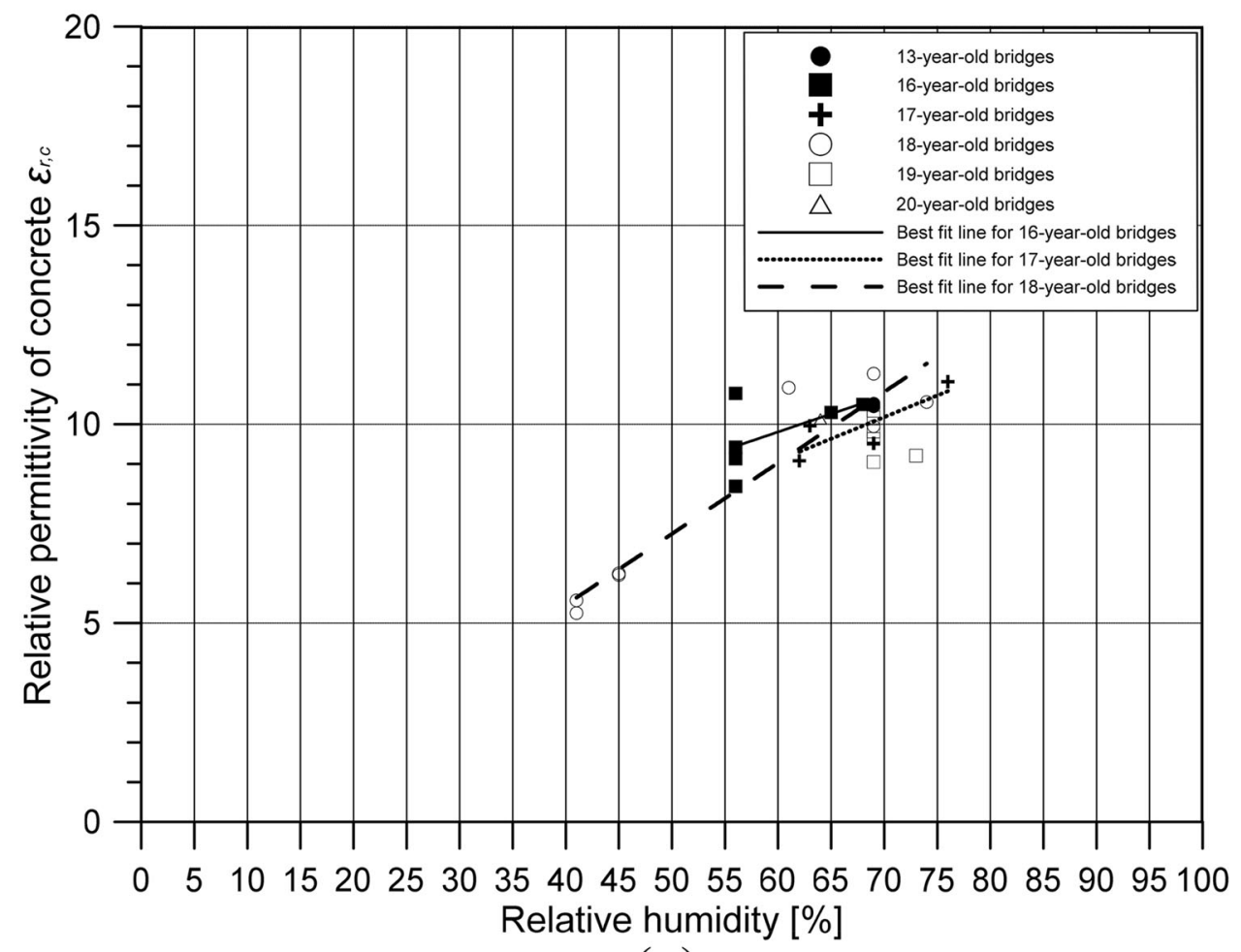

(a)

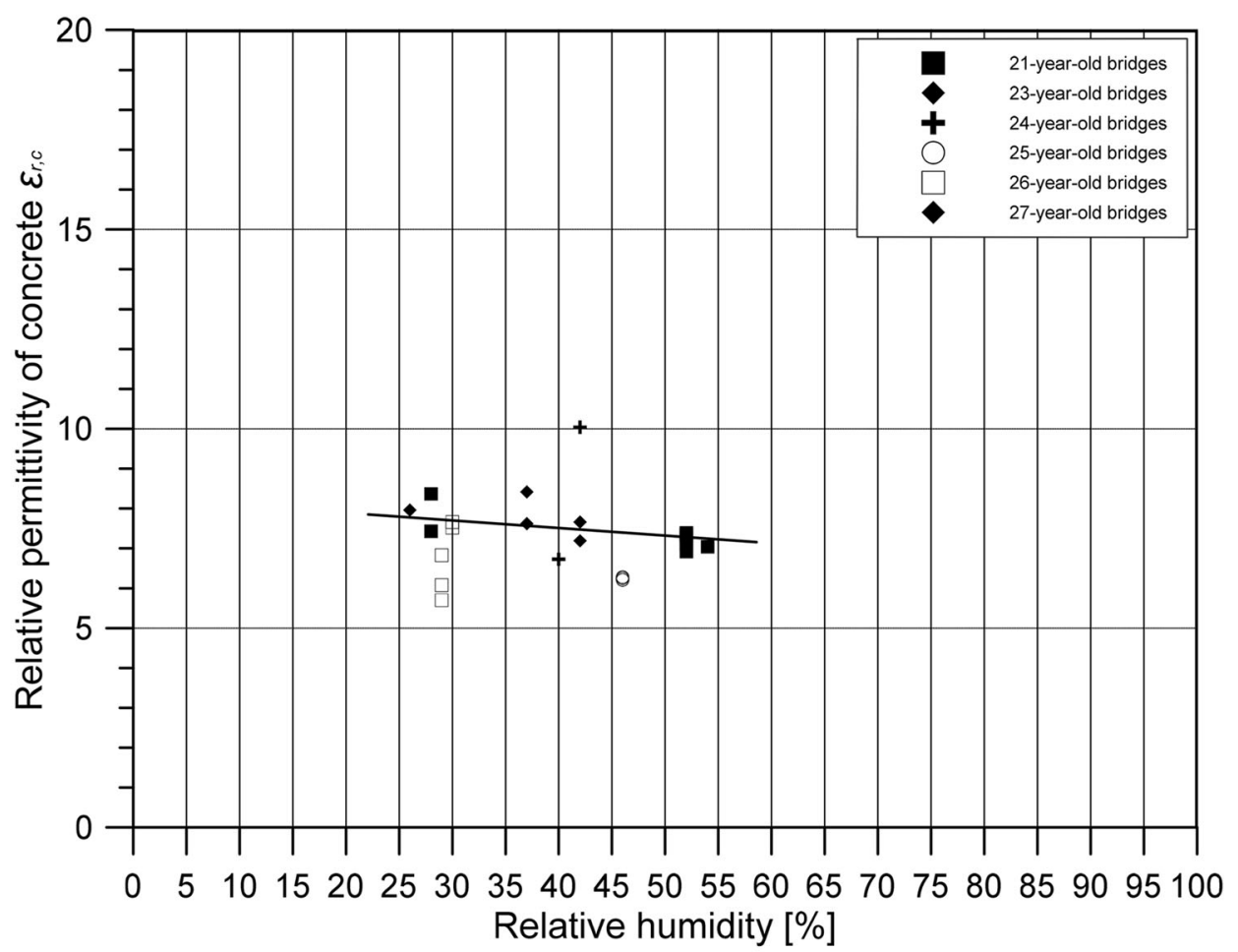

(b)

Fig. 8 Variation of relative permittivity of concrete with relative humidity of air: a group 1: concrete age lower than 20 years at the moment of GPR measurements and $\mathbf{b}$ group 2: concrete age greater than 20 years.

Korea expressways considered in this study was obtained by using a non-linear regression analysis, as follows,

$$
\varepsilon_{r, c}^{A g e}=-1.63 \ln \left(\text { Age }_{\text {conc }}\right)+12.17\left(R^{2}=0.84\right)
$$

where $A g e_{\text {conc }}$ is the age of the concrete at the time of the GPR measurements. The R-squared value of 0.84 was far International Journal of Concrete Structures and Materials more improved in comparison to that of the best fit curve before suppressing the relative humidity effect. This equation will be useful for understanding the age-dependent features of the relative permittivity of concrete, and to provide a reasonable assumption of the relative permittivity of concrete for GPR application in the field. 


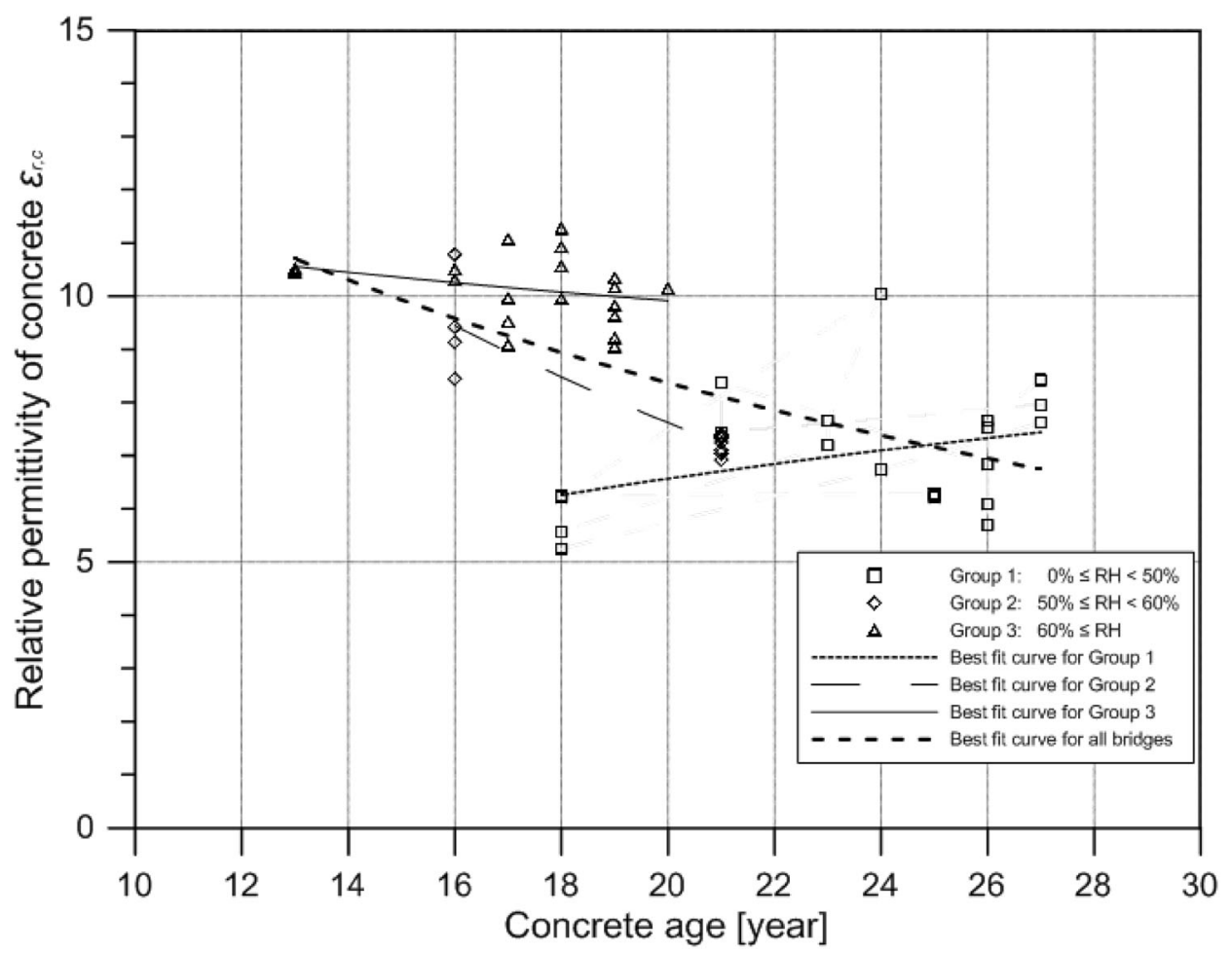

Fig. 9 Variation of relative permittivity of concrete in three bridge groups of similar relative humidity (RH) with concrete age: group 1 for $\mathrm{RH}$ lower than $50 \%$, group 2 for $\mathrm{RH}$ between 50 and $60 \%$, group 3 for $\mathrm{RH}$ equal to or greater than $60 \%$.

Note that the wider scattering of the relative permittivity of old deck concrete is the result of concrete damage and its effect on the relative permittivity. Consequently, it is reasonable to classify the relative permittivity of old concrete into two groups: (1) concrete decks in good condition, whose relative permittivity is within the range between 6.0 $(\mu-1.5 \sigma)$ and $10.8(\mu+1.5 \sigma)$, where $\mu$ is the mean value and $\sigma$ is the standard deviation of the relative permittivity and (2) potentially damaged concrete, with relative permittivity lower than 6.0 or higher than 10.8 .

\section{Evaluation of the Bare Deck Concrete Condition Using Relative Permittivity}

An evaluation of the conditions of the bare deck concrete of bridge JB-3S (to Tongyeong) and JB-3N (to Hanam) was carried out, taking into account the two influential factors affecting the relative permittivity of the concrete (i.e., the relative humidity of the air and the age of the concrete). Note that the concrete bridge used for validation was a prestressed concrete I-type girder (PSCI) bridge, from span 2 to span 5, which is different from the steel box girder (SBG), span 1, the bridge deck considered in the regression analysis in the previous section. For the evaluation, the condition of the relative permittivity of the concrete, assessed using the amplitude reflection method, was compared with the results of visual inspection, and the depth-corrected attenuation of radar waves reflected from the tops of rebar.

Figure 11 shows the condition map of the concrete deck surface on spans 2, 3, 4, and 5 of the validation bridge, as determined by visual inspection. There were different types of visual evidence showing the deterioration of concrete on the surface, including distributed surface-breaking cracks, spalling and repaired regions that had been patched with concrete and/or epoxy (see Fig. 12). Overall, the concrete decks on the JB-3N appeared to be more severely deteriorated than those on the JB-3S. In particular, the third span of JB-3N had combinations of different types of damage (e.g., surface-cracking, spalling, and repaired regions); the damaged area of this span was about $19.6 \%$ of the total span area (= $\left.65.9 \mathrm{~m}^{2} / 336 \mathrm{~m}^{2} \times 100[\%]\right)$. The damaged areas of each span on JB-3N and JB-3S are summarized in Table 4, based on condition maps prepared using visual inspection (see Fig. 11).

To better understand the concrete conditions, the distribution of clear cover depths to the top rebar in the validation bridges was obtained using GPR reflection data, and the results are illustrated in Fig. 13. In addition, corrosion potential was measured using a half-cell potential (HCP) meter (ASTM C 876 1999) at five locations on the validation bridge (see Fig. 11 for potential measurements: T1, T2, T3, T4 and T5), and the results were summarized in Table 5. It was found that the third span of JB-3N, which appeared to have the highest damage ratio, was constructed with a cover thickness over the top rebar that was much less than the design cover thickness of $90 \mathrm{~mm}$. In some areas the top cover thicknesses were 20 or $30 \mathrm{~mm}$ (Fig. 12b). In addition, the damaged areas of the bare concrete decks on other spans of the validation bridge mostly coincided with areas that had a clear cover that was less than the design value (see Figs. 11 and 13). Furthermore, the corrosion potential results obtained from the five HCP measurements in this study indicated that rebar under the less clear cover areas had a 

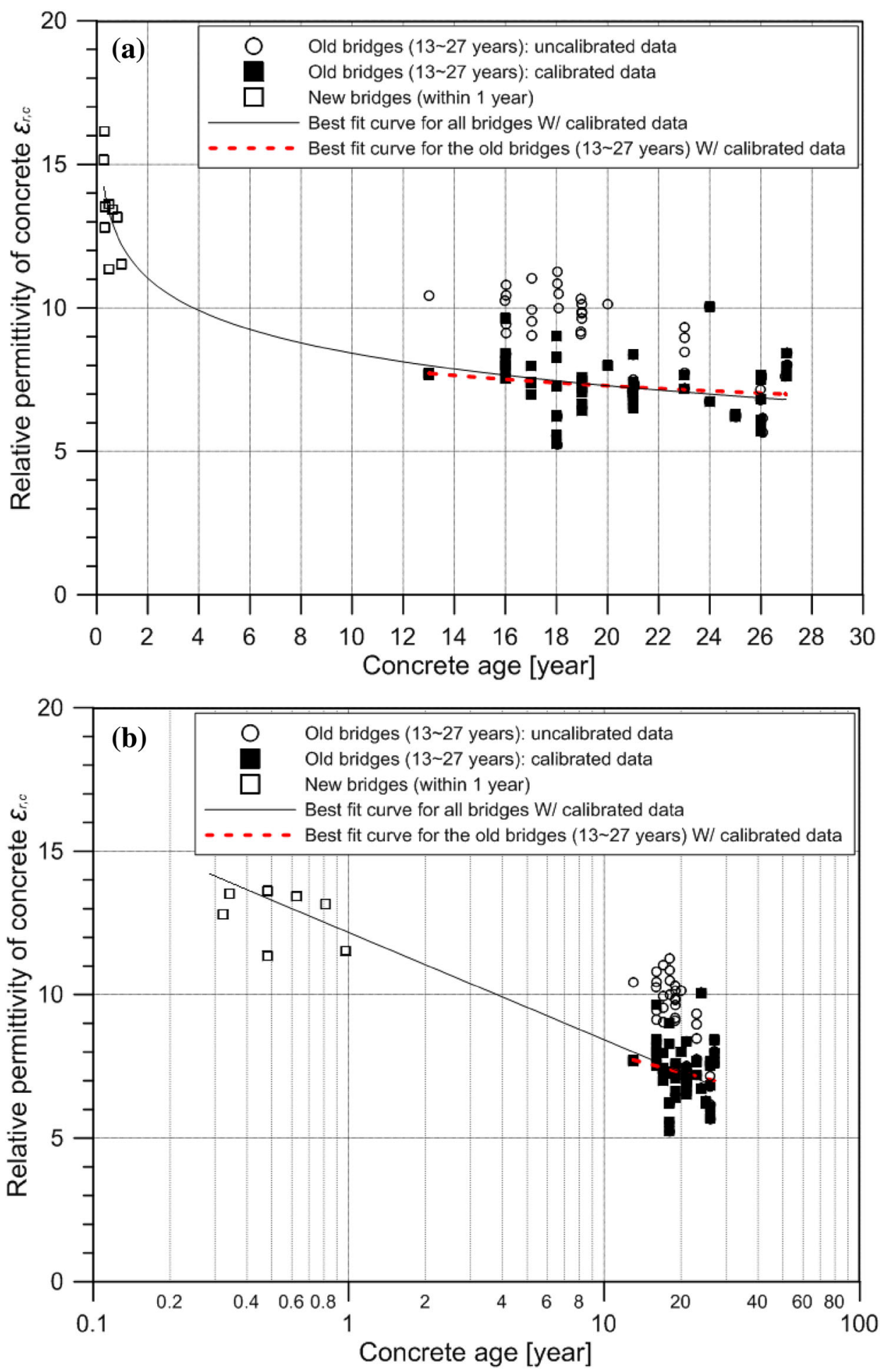

Fig. 10 Variation of calibrated relative permittivity of concrete in old bridges with concrete age: a linear- and $\mathbf{b}$ logarithmic scale in the horizontal axis for concrete age. For a comparison, data from new bridges and old bridges before calibration are shown in the same figure.

higher chance of corrosion activity, which might result in micro-cracking around the rebar, further accelerating corrosion and other deterioration mechanisms such as freezing and thawing (Suh et al. 2004b). In this regard, it was observed that damage to the bare concrete bridge decks on Korea expressways is manifested by greater porosity and/or micro cracking with higher permeability (Suh et al. 2004a).
Figure 14 shows the condition map of the deck concrete on the validation bridge based on the GPR survey. The horizontal and vertical axes of the deck surface in Fig. 14 represent the bridge length and the bridge width from the center line, respectively. The age of the concrete in the service period was 16 years, and the relative air humidity was $56 \%$ at the bridge on the survey day. The expected reference values of relative permittivity of 


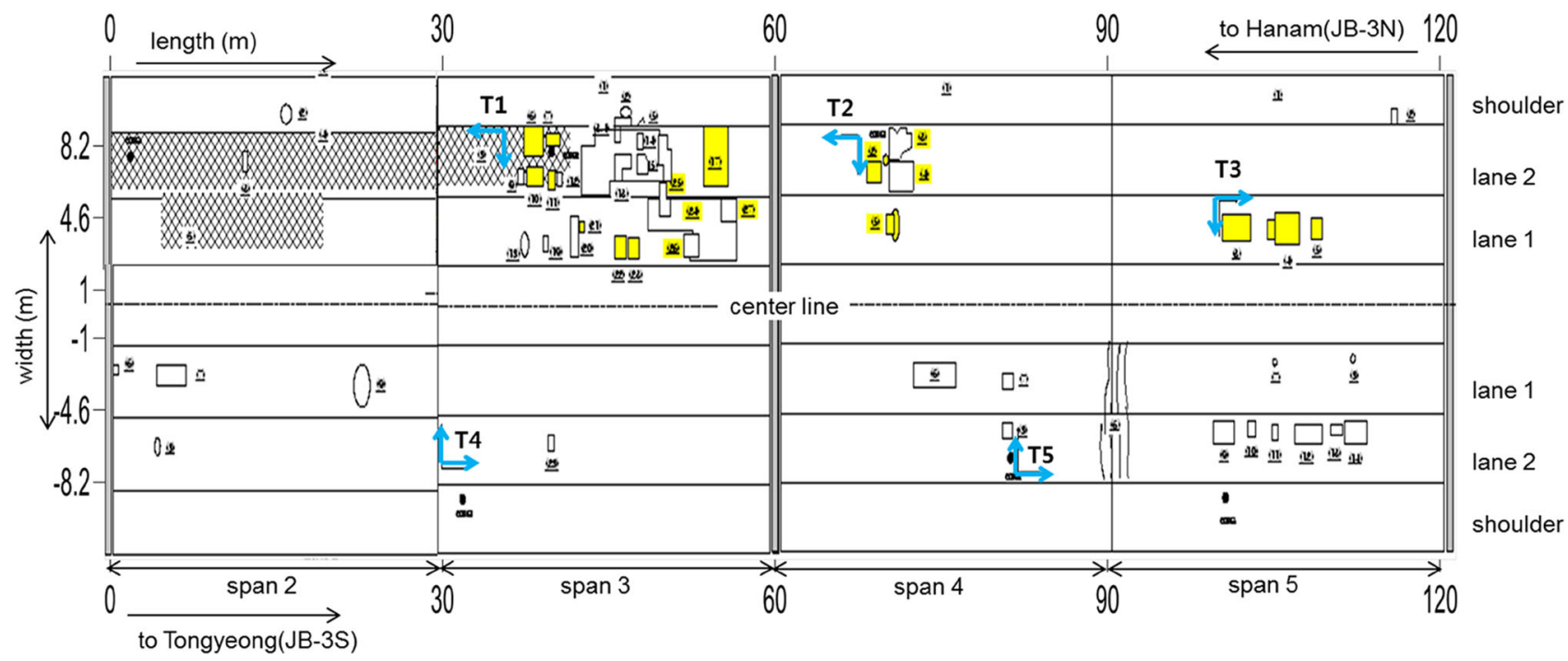

Fig. 11 Condition map of concrete bridge deck obtained from visual inspection. ( : one way cracks, filled square: map cracks, open circle: spalling, open square: repaired by concrete patch. $\square$ : repaired by epoxy patch, $\leftarrow:$ half-cell potential measurement).

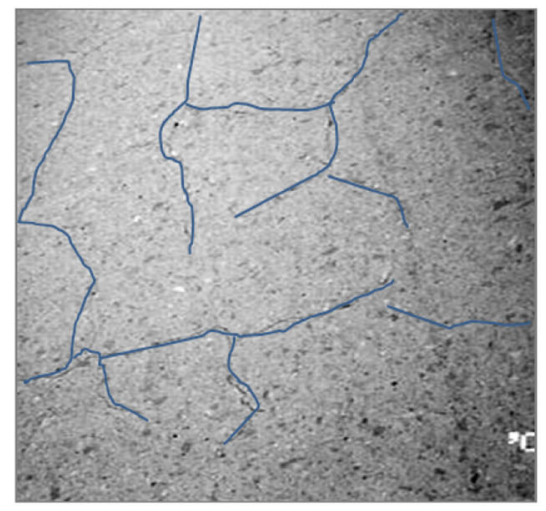

(a)

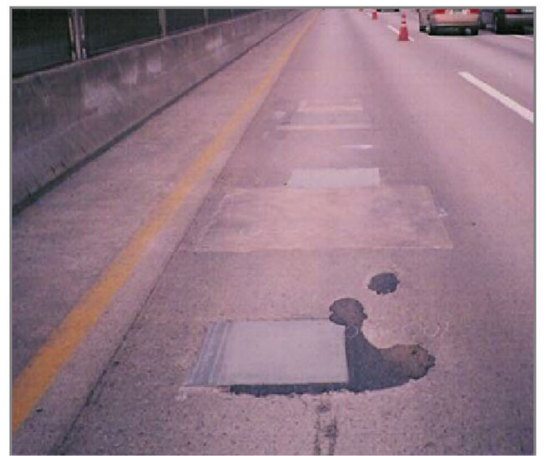

(d)

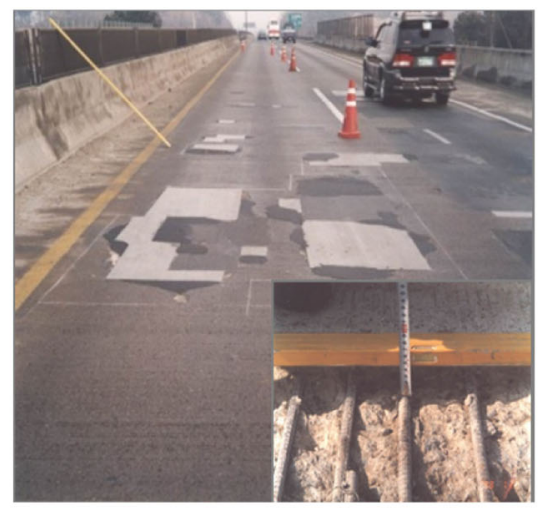

(b)

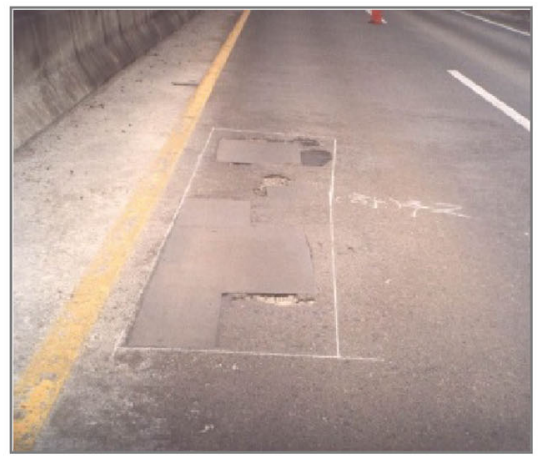

(e)

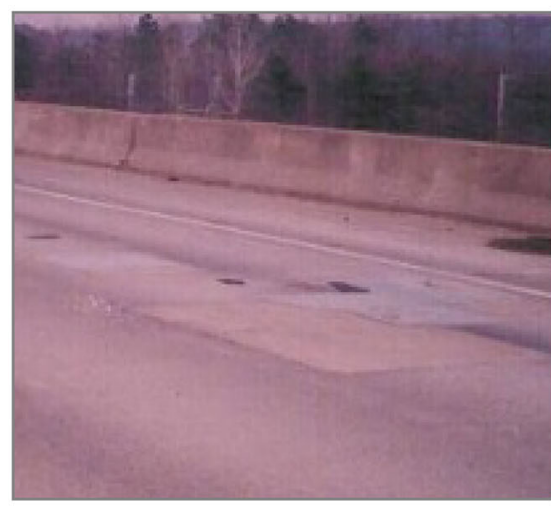

(c)

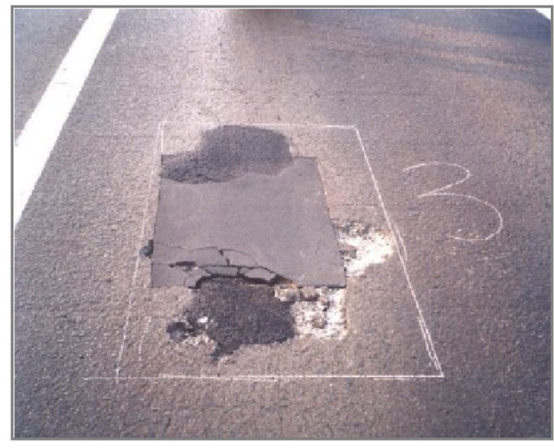

(f)

Fig. 12 Typical deterioration of concrete on the validation concrete bridge deck: a distributed surface-breaking crack [span 2 and lane 2, JB-3N], b region repaired by rapid-set concrete and epoxy patch [span 3 and lane 2, JB-3N], c region repaired by rapid-set concrete and epoxy patch [span 4 and lane 2, JB-3N], d region repaired by rapid-set concrete and epoxy patch [span 5 and lane 1, JB-3N], e spalling [span 2 and lane 1, JB-3S], and f spalling and region repaired by epoxy patch [span 5 and lane 2, JB-3S].

undamaged deck concrete was 8.4 , based on Eq. (8). Survey results of the relative permittivity using GPR on JB-3S and JB-3N were 8.4 and 9.8 , respectively. The average relative permittivity of JB-3S, of which less surface damages occurred, was the same as the predicted value, while that of JB-3N, of which more surface damages occurred, was a little larger than the predicted value. 
Table 4 Evaluation results on the validation concrete decks by various survey methods.

\begin{tabular}{|c|c|c|c|c|c|c|c|c|c|c|c|c|c|c|c|}
\hline \multirow{4}{*}{\multicolumn{2}{|c|}{ Location }} & \multicolumn{4}{|c|}{ Visual inspection } & \multicolumn{10}{|c|}{ GPR } \\
\hline & & \multirow{3}{*}{$\begin{array}{l}\text { Survey } \\
\text { area } \\
\left(\mathrm{m}^{2}\right)\end{array}$} & \multirow{2}{*}{\multicolumn{3}{|c|}{ Damage }} & \multirow{3}{*}{$\begin{array}{c}\text { Survey } \\
\text { area } \\
\left(\mathrm{m}^{2}\right)\end{array}$} & \multicolumn{6}{|c|}{ Relative permittivity } & \multirow{2}{*}{\multicolumn{3}{|c|}{\begin{tabular}{|c} 
Depth-corrected \\
attenuation (normalized, \\
$-3 \mathrm{~dB})$
\end{tabular}}} \\
\hline & & & & & & & \multicolumn{3}{|c|}{$\begin{array}{l}\text { Damage (over 12) } \\
\text { (current rule) }\end{array}$} & \multicolumn{3}{|c|}{$\begin{array}{c}\text { Damage (out of } 6 \sim 11) \\
\text { (suggested criteria) }\end{array}$} & & & \\
\hline & & & $\begin{array}{l}\text { Area } \\
\left(\mathrm{m}^{2}\right) \\
\end{array}$ & $\begin{array}{c}\text { Ratio } \\
(\%) \\
\end{array}$ & Rating & & $\begin{array}{l}\text { Area } \\
\left(\mathrm{m}^{2}\right) \\
\end{array}$ & $\begin{array}{c}\text { Ratio } \\
(\%) \\
\end{array}$ & Rating & $\begin{array}{c}\text { Area } \\
\left(\mathrm{m}^{2}\right) \\
\end{array}$ & $\begin{array}{c}\text { Ratio } \\
(\%) \\
\end{array}$ & Rating & $\begin{array}{l}\text { Area } \\
\left(\mathrm{m}^{2}\right) \\
\end{array}$ & $\begin{array}{c}\text { Ratio } \\
(\%)\end{array}$ & Rating \\
\hline \multirow[t]{5}{*}{ JB-3N } & Span 2 & 336 & 2.4 & 0.7 & $\mathrm{~b}$ & 271.8 & 3.6 & 1.3 & $\mathrm{~b}$ & 21.8 & 8.0 & $\mathrm{c}$ & 19.9 & 7.3 & $\mathrm{c}$ \\
\hline & Span 3 & 336 & 65.9 & 19.6 & d & 271.8 & 16.8 & 6.2 & $\mathrm{c}$ & 52.5 & 19.3 & $d$ & 60.6 & 22.3 & $\mathrm{e}$ \\
\hline & Span 4 & 336 & 16.8 & 5.0 & $\mathrm{c}$ & 271.8 & 49.4 & 18.2 & d & 125.0 & 46.0 & $\mathrm{e}$ & 60.4 & 22.2 & $\mathrm{e}$ \\
\hline & Span 5 & 336 & 8.9 & 2.6 & $\mathrm{c}$ & 271.8 & 48.8 & 18.0 & d & 63.8 & 19.0 & d & 48.3 & 17.8 & d \\
\hline & Total & 1344 & 93.9 & 7.0 & $\mathrm{c}$ & 1087.2 & 118.7 & 10.9 & $d$ & 263.1 & 19.5 & $d$ & 189.2 & 17.4 & $\mathrm{~d}$ \\
\hline \multirow[t]{5}{*}{ JB-3S } & Span 2 & 336 & 3.0 & 0.9 & $\mathrm{~b}$ & 274.5 & 1.3 & 0.5 & $\mathrm{~b}$ & 3.4 & 1.2 & b & 23.2 & 8.4 & $\mathrm{c}$ \\
\hline & Span 3 & 336 & 0.3 & 0.1 & b & 274.5 & 3.6 & 1.3 & b & 19.2 & 7.0 & $\mathrm{c}$ & 11.2 & 4.1 & $\mathrm{c}$ \\
\hline & Span 4 & 336 & 5.7 & 1.7 & $\mathrm{~b}$ & 274.5 & 4.7 & 1.7 & b & 9.1 & 3.3 & $\mathrm{c}$ & 21.2 & 7.7 & $\mathrm{c}$ \\
\hline & Span 5 & 336 & 8.7 & 2.6 & $\mathrm{c}$ & 274.5 & 1.6 & 0.6 & b & 6.1 & 2.2 & $\mathrm{c}$ & 23.7 & 8.6 & $\mathrm{c}$ \\
\hline & Total & 1344 & 17.7 & 1.3 & $\mathrm{~b}$ & 1098 & 11.2 & 1.0 & $\mathrm{~b}$ & 37.7 & 3.4 & $\mathrm{c}$ & 79.3 & 7.2 & $\mathrm{c}$ \\
\hline
\end{tabular}

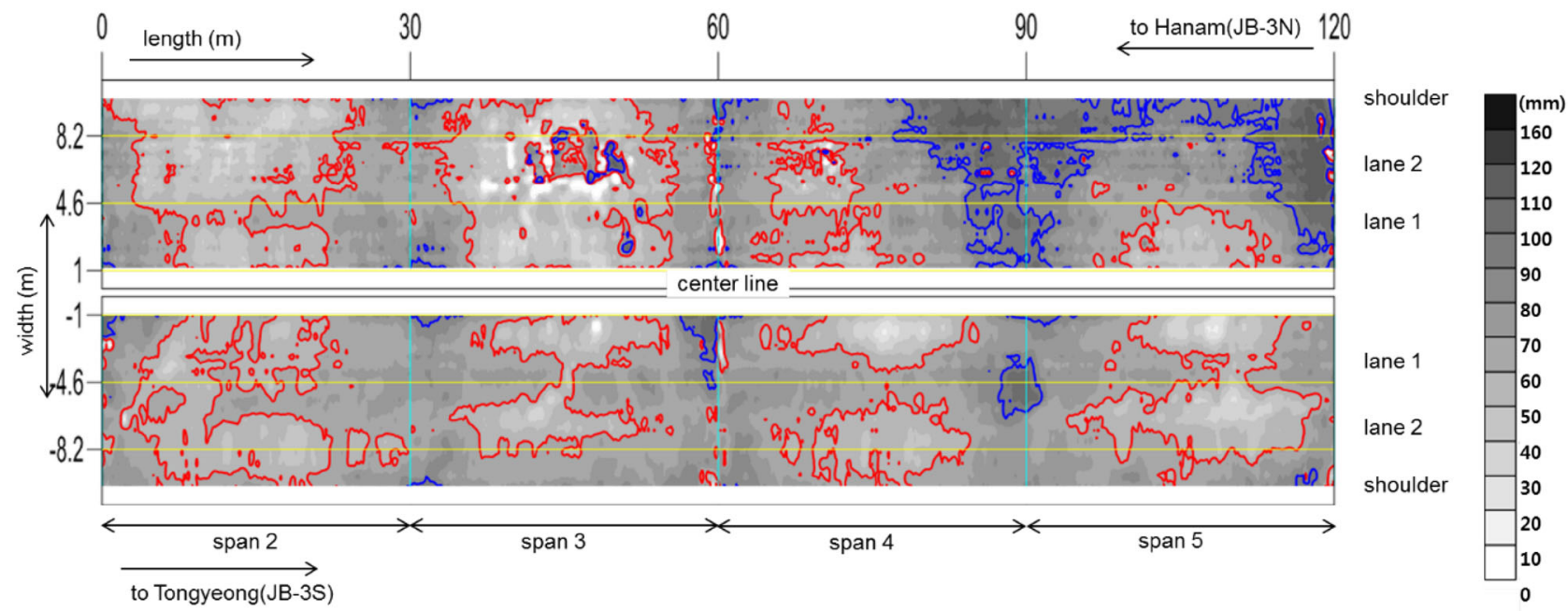

Fig. 13 Distribution of cover thickness of top rebar; red and blue lines represent $60 \mathrm{~mm}$ and 90 mm thickness, respectively.

Table 5 Corrosion potential measured by half-cell method.

\begin{tabular}{|c|c|c|c|c|c|c|}
\hline \multicolumn{3}{|c|}{ Location } & \multicolumn{3}{|c|}{ Areal percentage of potential $\mathrm{E}$} & \multirow[t]{2}{*}{ Note } \\
\hline Bridge & Span & Lane & $\mathrm{E}<-350^{\mathrm{a}}$ & $-350 \leq \mathrm{E} \leq-200^{\mathrm{b}}$ & $-200<\mathrm{E}^{\mathrm{c}}$ & \\
\hline \multirow[t]{3}{*}{ JB-3N } & 3 & 2 & 0.0 & 0.2 & 99.8 & $\mathrm{~T} 1$ \\
\hline & 4 & 2 & 27.9 & 71.6 & 0.5 & $\mathrm{~T} 2$ \\
\hline & 5 & 1 & 14.0 & 48.3 & 37.6 & $\mathrm{~T} 3$ \\
\hline \multirow[t]{2}{*}{ JB-3S } & 3 & 2 & 0.0 & 0.0 & 100.0 & $\mathrm{~T} 4$ \\
\hline & 4 & 2 & 0.0 & 15.1 & 84.9 & T5 \\
\hline
\end{tabular}

\footnotetext{
${ }^{\text {a }}$ Greater than $90 \%$ probability of rebar corrosion.

${ }^{\mathrm{b}}$ Corrosion activity of the rebar in that area is uncertain.

c $90 \%$ probability that there is no rebar corrosion ( $10 \%$ risk of rebar corrosion).
} 

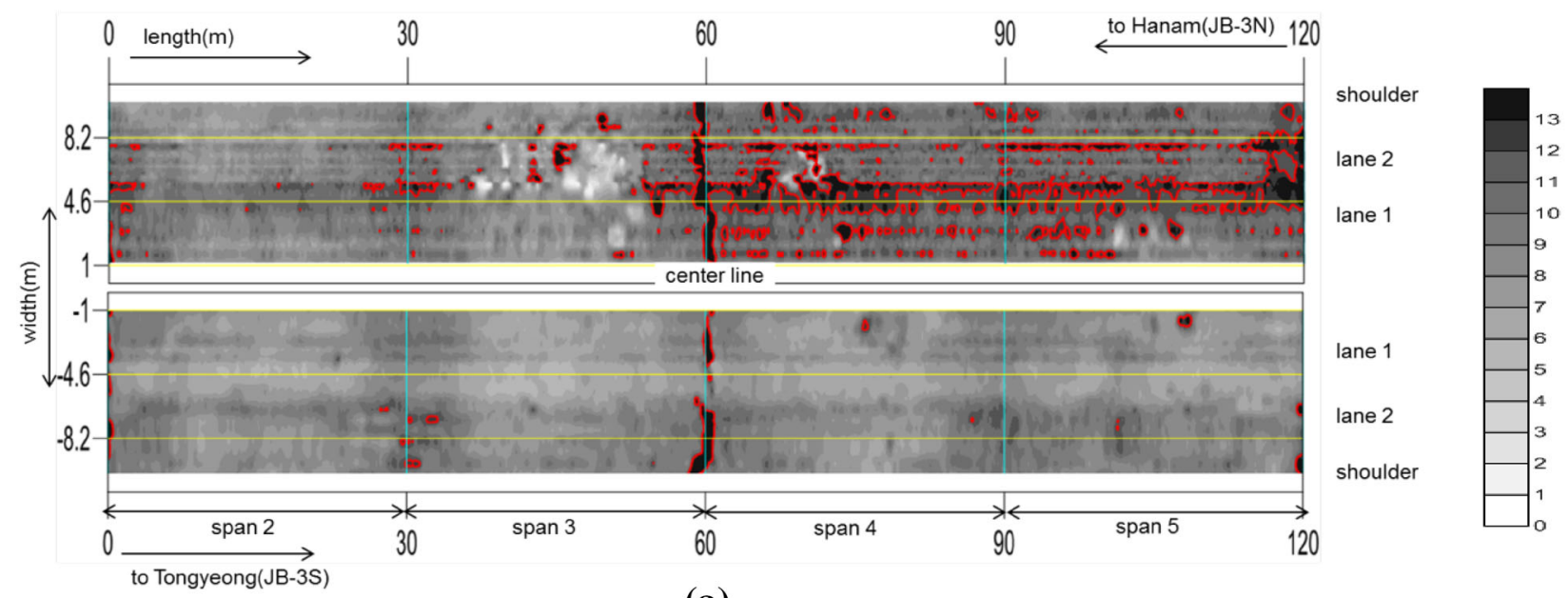

(a)
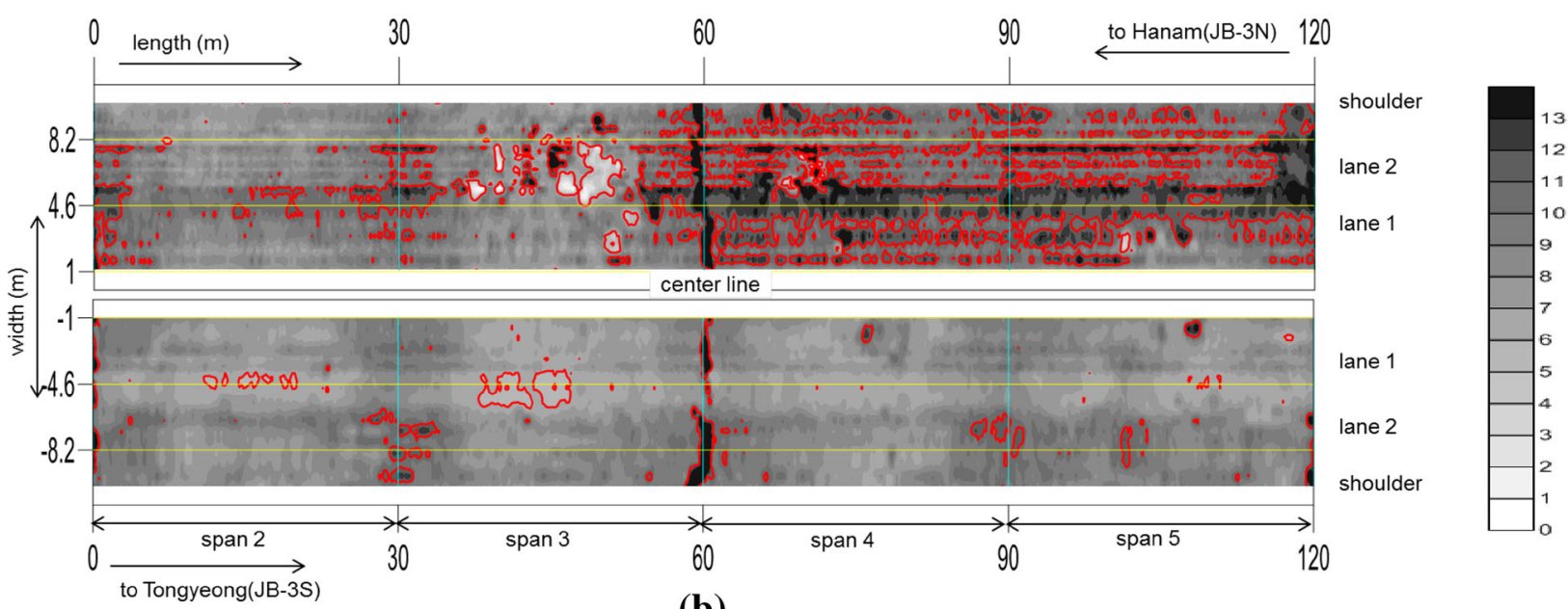

(b)

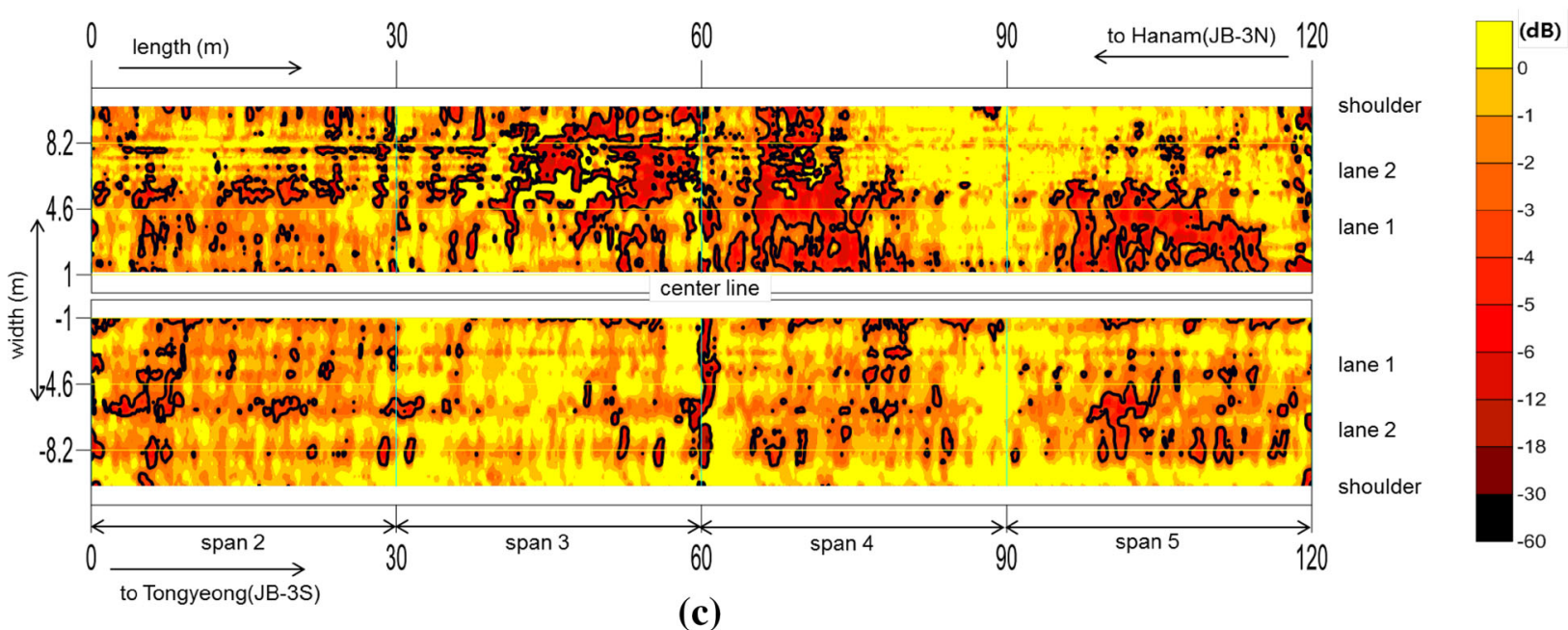

Fig. 14 Condition maps of concrete bridge decks obtained from air-coupled GPR measurements. a cut-off relative permittivity over 12 , b cut-off relative permittivity under 6 and over 11, and $\mathbf{c}$ depthcorrected attenuation map based on the reflection from the top rebars.

The red line in Fig. 14a represents the cut-off relative permittivity of 12.0. The areas with a relative permittivity over 12.0 were judged to be damaged or potentially damaged according to the current interpretation of rules for
Korea expressways (Suh et al. 2000). However, some areas of lane 2 of span 3 of JB-3N, where damages were most concentrated, and some other areas in JB-3S, were not accurately classified as damaged areas by the current single 
cut-off relative permittivity criteria. Furthermore, the damaged areas calculated from the single cut-off relative permittivity criteria were smaller than those determined by visual inspection.

On the contrary, Fig. 14b shows a concrete condition map based on a dual cut-off relative permittivity: regions were judged to be damaged when the cut-off relative permittivity was lower than 6.0 or higher than 11.0. The two thresholds of relative permittivity were determined from $\mu-1.5 \sigma$ and $\mu+1.5 \sigma$, where $\mu$ and $\sigma$ are the average and standard deviations of relative permittivity of the old concrete bridge decks in this study. Overall, the condition map based on the dual cut-off criteria (see Fig. 14b) appears to be more closely correlated with the visual inspection map than the condition map based on a single cut-off relative permittivity criteria (see Fig. 14a). The most severely damaged areas of lane 2 of span 3 of JB-3N, and the other damaged areas on JB-3N, which were hardly detected in Fig. 14a, were successfully classified as damaged areas in Fig. 14b. It is noteworthy that the damaged areas estimated by the dual cut-off relative permittivity criteria are larger than those judged by visual inspection (especially on spans 4 and 5 on JB-3N). This phenomenon is related to the improved capability of GPR that is able to detect even minor damages, such as microcracks filled with air and/or water, which are generally missed by visual inspection. For example, the relative permittivity of the concrete was found to be larger over the concrete girders (at the vertical axes of $-9.0,-6.6,-4.2$, $-1.8,3.0,5.4$, and $7.8 \mathrm{~m}$ ) and near piers (at the horizontal axes of 30 and $90 \mathrm{~m}$ ). Those regions are subjected to tensile cracking by the negative moment produced by traffic loads. Therefore, it is demonstrated that the relative permittivity data of GPR signals based on the surface reflection method could be a good indicator of the concrete damage, especially on the surface or sub-surface regions. Deteriorated concrete regions with greater porosity and/or surface-breaking cracks (or concrete with high permeability) can be detected as the regions with higher or lower relative permittivity value than that of solid concrete in wet or dry, respectively, condition.

For comparison, a concrete condition map based on the depth-corrected attenuation of GPR signals reflected from the upper layer of rebar is shown in Fig. 14c. In the sound concrete, the attenuation of radar waves is generally proportional to the depth of the rebar, detailing the two way travel time. For JB-3N and $3 \mathrm{~S}$, it was assumed that $50 \%$ of the concrete was sound and the critical value of the depth corrected attenuation was $-3 \mathrm{~dB}$ (Rhee et al. 2016). Table 4 summarizes the estimated damaged areas of each of the spans based on the condition maps obtained from the three different GPR analysis methods (i.e., single- and dual cut-off relative permittivity and depth-corrected attenuation criteria). In addition, the damaged areas of each span were calculated according to the 'Inspection manual for the bridge (Minister of Land Infrastructure and Transport, Korea Infrastructure Safety and Technology Corporation 2012)'. Figure 14 shows some disagreements between the attenuation and relative permittivity analyses. The discrepancy stems from the fact that the relative permittivity value measured from the GPR signal reflection method is mainly attributed to the properties of the surface of concrete, and, accordingly, it does not directly provide information on the concrete condition of the rebar layer. However, overall damage indices that were based on the dual cut-off relative permittivity showed a fairly good correlation with those evaluated from the depth-corrected attenuation criteria, although the damage indices that were based on the single value-based criteria tended to underestimate the concrete's condition. This field observation on Korea expressways indicated that the relative permittivity measurements using the GPR surface refection method was effective in evaluating the surface condition of concrete bridge decks as shown in part good agreement with the attenuation method.

\section{Summary and Conclusions}

In this study GPR tests on bare deck concrete bridges in public service were carried out to determine the relationship between the relative permittivity of the concrete deck and the factors that influence its deterioration, namely, the age of the concrete and its water content. Subsequently, an evaluation of the condition of the bare deck concrete bridges was performed using relative permittivity in relation to the main factors of influence. A summary of the results of this study can be drawn as follows:

(1) The relative permittivity of concrete in the eight new bridges with ages under 1 year ranged between 11 and 16 , with an average of 13.3 and a standard deviation of 1.5. The values rapidly decreased within a half year. The GPR surveys were conducted at least $24 \mathrm{~h}$ after any precipitation on the bridges, consistent with the field survey protocol of Korea Expressway Corporation. Accordingly, the observed variations in relative permittivity of early-age concrete were mainly attributed to water in the concrete pore system. Basically, the relative permittivity of concrete in a hydrated state decreases rapidly with age, and that state can last up to one year. For this reason, special care should be taken when evaluating the condition of new bridges, within one year after casting, using a GPR survey.

(2) For the old bridges with ages over 10 years, the relative permittivity of concrete tended to slowly decrease as the concrete age increased. This indicates that the microstructure of the concrete became stable as the residual water evaporated with aging. Consequently, the relative permittivity of the concrete gradually decreases and converges to a certain range as the age of the concrete increases.

(3) However, the relative permittivity of concrete in the old bridges were strongly influenced by seasonal variations. A statistical analysis showed that the relative humidity of the air was the most influential factor affecting the relative permittivity of the concrete, among the four main weather factors (temperature, rainfall, wind speed, and relative humidity). The relative permittivity of concrete 
measured using the surface reflection method is informative of near-surface conditions of the bare concrete bridge decks, where the water ratio is reasonably assumed to be close to the relative humidity of the air. Therefore, seasonal variations in relative humidity should be properly taken into account for more accurate interpretation of concrete conditions when using relative permittivity measurements.

(4) It was demonstrated that the damaged areas of the bare concrete decks on the validation bridge mostly coincided with the areas that had clear covers that were less than the design value $(90 \mathrm{~mm})$. The corrosion potentials measured on the five selected locations of the validation bridge showed that the rebar beneath a reduced clear cover depth had a higher chance of corrosion activity. Generally, corroded rebars in concrete will result in micro-cracking around the rebar, which further accelerates the deterioration of the concrete by other factors such as freezing and thawing.

(5) Regions of concrete were judged to be damaged when the relative permittivity of the concrete was lower than 6.0 or higher than 11.0. This two threshold relative permittivity was determined from $\mu-1.5 \sigma$ and $\mu+1.5 \sigma$, where $\mu$ and $\sigma$ are the average and the standard deviation of relative permittivity of the old concrete bridge decks in this study. It was demonstrated that the relative permittivity of concrete based on the surface reflection of GPR signals could be a good indicator of concrete damage (e.g., greater porosity and/or surface-breaking cracks), especially on the surface or sub-surface regions. In addition, the condition map based on the dual cut-off relative permittivity criteria showed a good agreement with the attenuation method, in comparison to that based on the conventional single cut-off relative permittivity criteria in Korea expressways.

\section{Acknowledgments}

This research was supported and funded by Korea Expressway Corporation Research Institute (KECRI), and Basic Science Research Program through the National Research Foundation of Korea (NRF) funded by the Ministry of Education (2016R1A6A1A03012812).

\section{Open Access}

This article is distributed under the terms of the Creative Commons Attribution 4.0 International License (http:// creativecommons.org/licenses/by/4.0/), which permits unrestricted use, distribution, and reproduction in any medium, provided you give appropriate credit to the original author(s) and the source, provide a link to the Creative Commons license, and indicate if changes were made.

\section{References}

American Society for Testing and Materials (ASTM). (1999). Standard test method for half-cell potentials of uncoated reinforceing steel in concrete (ASTM C 876). West Conshohocken: ASTM International.

American Society for Testing and Materials (ASTM). (2011). Standard guide for using the surface ground penetrating radar method for subsurface investigation (ASTM D 6432). West Conshohocken: ASTM International.

Balanis, C. A. (1989). Advanced engineering electromagnetics. New York: Wiley.

Barnes, C. L., Trottier, J. F., \& Forgeron, D. (2008). Improved concrete bridge deck evaluation using GPR by accounting for signal depth-amplitude effects. NDT and E International, 41(6), 427-433.

Berhane, Z. (1984). Evaporation of water from fresh mortar and concrete at different environmental conditions. Journal Proceedings, 81(6), 560-565.

Bourdi, T., Rhazi, J. E., Boone, F., \& Ballivy, G. (2012). Modelling dielectric-constant values of concrete: An aid to shielding effectiveness prediction and ground-penetrating radar wave technique interpretation. Journal of Physics. D. Applied Physics, 45(40), 405401.

Construction Division. (1988). Seoul-Cheongju Jungbu expressway construction magazine. Seongnam: Korea Expressway Corporation. (in Korean).

Construction Planning Department. (2004a). Chungju-Sangju expressway construction magazine. Seongnam: Korea Expressway Corporation. (in Korean).

Construction Planning Department. (2004b). Sangju-Gumi expressway construction magazine. Seongnam: Korea Expressway Corporation. (in Korean).

Daniels, D. J. (2004). Ground penetrating radar: IET radar, sonar, navigation and avionics series 15. London, UK: The Institution of Engineering and Technology.

Dinh, K., Gucunski, N., Kim, J., \& Duong, T. H. (2016). Understanding depth-amplitude effects in assessment of GPR data from concrete bridge decks. NDT and E International, 83, 48-58.

Geophysical Survey Systems, Inc., (GSSI). (2009). RADAN Version 6.6. GSSI, Salem, NH, USA.

Gucunski, N., Imani, A., Romero, F., Nazarian, S., Yuan, D., Wiggenhauser, H., Shokouhi, P., \& Taffe, A. (2013). Nondestructive testing to identify concrete bridge deck deterioration (S2-R06A-RR-1). SHRP 2 Report, Transportation Research Board (TRB), Washington, D.C., USA.

Hasan, M. I., \& Yazdani, N. (2014). Ground penetrating radar utilization in exploring inadequate concrete covers in a new bridge deck. Case Studies in Construction Materials, 1, 104-114.

Klysz, G., Balayssac, J. P., \& Ferrieres, X. (2008). Evaluation of dielectric properties of concrete by a numerical FDTD model of a GPR coupled antenna-parametric study. NDT and E International, 41(8), 621-631.

Korea Meteorological Administration. Retrieved from http:// www.kma.go.kr. Accessed July 2017. 
Lee, I. K., Kim, W. S., Kang, H. T., \& Seo, J. W. (2015). Analysis and prediction of highway bridge deck slab deterioration. Journal of the Korea Institute for Structural Maintenance and Inspection, 19(2), 068-075. (in Korean).

Maser, K. R., \& Scullion, T. (1991). Automated detection of pavement layer thicknesses and subsurface moisture using Ground Penetrating Radar, TRB Paper.

Minister of Land Infrastructure and Transport (MLIT), Korea Infrastructure Safety and Technology Corporation (KISTC). (2012). Inspection Manual for the Bridge. Ilsan: Korea Infrastructure Safety and Technology Corporation. (in Korean).

Rhee, J., \& Choi, J. (2017). Relative permittivity of damaged concrete bridge deck according to the weather condition: A case study. Journal of the Korea Academia-Industrial cooperation Society, 18(4), 209-215. https://doi.org/10. 5762/KAIS.2017.18.4.209. (in Korean).

Rhee, J., Choi, J., Kim, H., Park, K., \& Choi, M. (2016). A study on the integrity assessment of bare concrete bridge deck based on the attenuation of radar signals. Journal of the Korea Institute for Structural Maintenance and Inspection, 20(4), 84-93. https://doi.org/10.11112/jksmi. 2016.20.4.084. (in Korean).

Rhee, J., Kim, H., Ock, C., \& Choi, J. (2017). An investigation of the deterioration characteristics of concrete bridge decks with asphalt concrete in Korea. KSCE Journal of the Korea Engineering. https://doi.org/10.1007/s12205-017-1894-x.

Saarenketo, T. (1998). Electrical properties of water in clay and silty soils. Journal of Applied Geophysics, 40(1), 73-88.

Suh, J. W., Lee, I. Y., \& Rhee, J. Y. (1998). Evaluation of Concrete Bridge Deck Conditions. Highway Research Center, Korea Highway Corporation, Report No. 98-67-65.
Suh, J. W., Rhee, J. Y., \& Cheong, H. M. (2004a). A study on the construction and maintenance of bare concrete bridge decks (RT-ST-04-03). Hwaseong: Korea Highway Research Center. (in Korean).

Suh, J. W., Rhee, J. Y., \& Lee, I. Y. (2000). Condition evaluation of concrete bridge decks by using GPR. Road Engineering Association of Asia and Australasia Conference (REAAA), 10th, Tokyo, Japan.

Suh, J. W., Rhee, J. Y., Seo, S. G., \& Shin, J. I. (2004b). Condition evaluation of bare concrete bridge decks. Journal of The Korea Institute for Structural Maintenance Inspection, 8(3), 217-224. (in Korean).

Tarussov, A., Vandry, M., \& De La Haza, A. (2013). Condition assessment of concrete structures using a new analysis method: Ground-penetrating radar computer-assisted visual interpretation. Construction and Building Materials, 38, 1246-1254.

The Ministry of Construction Division. (1984). 88 Olympic Expressway Construction Magazine. Gwacheon, South Korea: The Ministry of Construction Division. (in Korean).

Varnavina, A. V., Khamzin, A. K., Torgashov, E. V., Sneed, L. H., Goodwin, B. T., \& Anderson, N. L. (2015). Data acquisition and processing parameters for concrete bridge deck condition assessment using ground-coupled ground penetrating radar: Some considerations. J Appl Geophys, $114,123-133$.

Yanhui, Z., Bei, Z., Wenbo, S., \& Tao, W. (2012). Experimental research on relationships between dielectric constant of cement concrete materials and measuring frequency. 2012 14th International Conference on Ground Penetrating Radar, pp. 403-406, Shanghai, China. 